\title{
RESEARCH
}

\section{Peripheral T3 signaling is the target of pesticides in zebrafish larvae and adult liver}

\author{
Marco Colella ${ }^{1,2, *}$, Valeria Nittoli2,*, Alfonsina Porciello $2, *$, Immacolata Porreca ${ }^{3}$, Carla Reale ${ }^{2}$, Filomena Russo ${ }^{2}$, \\ Nicola Antonino Russo ${ }^{2}$, Luca Roberto2 ${ }^{2}$ Francesco Albano 2,4 , Mario De Felice ${ }^{4,5}$, Massimo Mallardo5, ${ }^{5}$ and \\ Concetta Ambrosino $1,2,4, t$
}

1Department of Science and Technology, University of Sannio, Benevento, Italy

2IRGS, Biogem, Ariano Irpino, Avellino, Italy

Wellcome Trust Sanger Institute, Wellcome Genome Campus, Hinxton, Cambridge, UK

4IEOS-CNR, Naples, Italy

${ }^{5}$ Molecular Medicine and Medical Biotechnologies, University of Naples 'Federico II', Naples, Italy

Correspondence should be addressed to C Ambrosino: coambros@unisannio.it

*(M Colella, V Nittoli and A Porciello contributed equally to this work)

t(M Mallardo and C Ambrosino contributed equally as last authors)

\begin{abstract}
The intra-tissue levels of thyroid hormones (THs) regulate organ functions. Environmental factors can impair these levels by damaging the thyroid gland and/or peripheral TH metabolism. We investigated the effects of embryonic and/or long-life exposure to low-dose pesticides, ethylene thiourea (ETU), chlorpyrifos (CPF) and both combined on intra-tissue $\mathrm{T}_{4} / \mathrm{T}_{3}$ metabolism/signaling in zebrafish at different life stages. Hypothyroidism was evident in exposed larvae that showed reduced number of follicles and induced tshb mRNAs. Despite that, we found an increase in free $T_{4}$ (fT4) and free $T_{3}$ (fT3) levels/signaling that was confirmed by transcriptional regulation of TH metabolic enzymes (deiodinases) and T3-regulated mRNAs (cpt1, igfbp1a). Second-generation larvae showed that thyroid and TH signaling was affected even when not directly exposed, suggesting the role of parental exposure. In adult zebrafish, we found that sex-dependent damage of hepatic $\mathrm{T}_{3}$ level/signaling was associated with liver steatosis, which was more pronounced in females, with sex-dependent alteration of transcripts codifying the key enzymes involved in 'de novo lipogenesis' and $\beta$-oxidation. We found impaired activation of liver $\mathrm{T}_{3}$ and PPAR $\alpha / F o x o 3 a$ pathways whose deregulation was already involved in mammalian liver steatosis. The data emphasizes that the intratissue imbalance of the $T_{3}$ level is due to thyroid endocrine disruptors (THDC) and suggests that the effect of a slight modification in $\mathrm{T}_{3}$ signaling might be amplified by its direct regulation or crosstalk with PPAR $/$ Foxo3a pathways. Because $T_{3}$ levels define the hypothyroid/hyperthyroid status of each organ, our findings might explain the pleiotropic and site-dependent effects of pesticides.
\end{abstract}

\section{Key Words}

- HPT axis-disrupting chemicals

- lipid metabolism

- peripheral T3 metabolism/ signaling

- liver steatosis, deiodinases 


\section{Introduction}

Thyroid diseases and associated pathologies, such as obesity, non-alcoholic fatty liver disease (NAFLD), and so on, are widespread (Mehran et al. 2017). Genetic and environmental factors contribute to their onset by damaging the synthesis of thyroid hormones (THs) or their metabolism/signaling in peripheral organs (Vanderpump 2011).

The thyroid secretes the prohormone thyroxine $\left(\mathrm{T}_{4}\right)$, and to a lesser extent triiodothyronine $\left(\mathrm{T}_{3}\right)$, which is the most active form. $\mathrm{T}_{3}$ is produced mainly in peripheral organs (e.g. liver) in which TH metabolizing enzymes (deiodinases) can either activate or inactivate them, without necessarily affecting the circulating $\mathrm{T}_{3}$ level. $\mathrm{TH}$ signaling relies on both the circulating and the tissue/cellspecific levels of $\mathrm{T}_{3}$ and, finally, on TH receptors (THRs). Local $\mathrm{T}_{3}$ levels depend on an ensemble of tissue/cellspecific factors, such as deiodinases and $\mathrm{TH}$ transporters, which is relatively independent of serum TH levels (Colella et al. 2020). The peripheral modification of $\mathrm{T}_{4}$ and $\mathrm{T}_{3}$ defines the hypothyroidism or hyperthyroidism of different organs and the resulting dysfunction of target cells (i.e. hepatocytes). Hepatic $\mathrm{T}_{3}$ signaling ( $\mathrm{hT}_{3}$ signaling) is modulated by the binding of $\mathrm{T}_{3}$ to THRB, which regulates the expression of several hepatic genes, including transcripts involved in lipid metabolism (Oppenheimer et al. 1987).

Epidemiological and experimental data provide evidence that different environmental pesticides, including carbamates, such as mancozeb and ethylene thiourea (ETU; its metabolite), and organophosphorus pesticides, such as chlorpyrifos (CPF), might impair $\mathrm{TH}$ levels (Chhabra et al. 1992, IARC 2001, Belpoggi et al. 2002, Jeong et al. 2006, De Angelis et al. 2009, Axelstad et al. 2011). Although CPF has been banned in some countries, both CPF and ETU are widely used, and it is practically impossible not to be exposed from an early age. Studies conducted in developmentally exposed mice pointed to potential effects on thyroid function at otherwise non-toxic levels (Porreca et al. 2016). However, rodent models did not indicate if the thyroid damage was due to the direct activity of pesticides on fetuses or on maternal TH level/signaling.

Because of the external development and the transparency of developing embryos, zebrafish are a useful model for examining the effects of exposure to environmental factors during embryonic development in promoting disease in adult life. This permits easy incubation of the embryos in a chemical solution for the examination of stage-specific exposure effects (Eddins et al. 2010, Levin et al. 2011, Richendrfer et al. 2012, Richendrfer \& Creton 2013, Clift et al. 2014). Thyroid development in zebrafish closely resembles that of higher vertebrates. Despite some anatomical differences, the feedback loop active in the HPT axis and the intra-tissue/cell TH metabolism/signaling pathways are both evolutionarily conserved between fish and mammals. Some studies have reported differences (Darras et al. 2015, Marelli \& Persani 2017, Zada et al. 2017); tsh $\beta$ transcription is stimulated by $\mathrm{crh}$ (De Groef et al. 2006), and zebrafish deiodinase 1 (dio1) has little affinity for $\mathrm{T}_{4}$ and is mainly involved in $\mathrm{T}_{3}$ deactivation (Guo et al. 2014).

The data reported here demonstrate the impairment of thyroid development and of whole body $\mathrm{T}_{3}$ level/signaling in zebrafish larvae exposed to pesticides, and emphasizes the role of parental exposure. The data provides evidence that the $\mathrm{T}_{3}$ and PPARalpha/Foxo3a signaling pathways are targets of pesticides in adult livers.

\section{Materials and methods}

\section{Zebrafish stocks and husbandry}

Adult fish (AB line) were maintained according to standard procedures on a $14 \mathrm{~h}$ light: $10 \mathrm{~h}$ darkness cycle at $28^{\circ} \mathrm{C}$ as previously described (Westerfield 1995). Embryos were obtained by natural spawning and staged based on hours post-fertilization (hpf) or days post-fertilization (dpf) according to morphological criteria (Kimmel et al. 1995). Animal experiments were performed in accordance with the European Council Directive 2010/63/EU. Procedures were approved by the Italian Ministry of Health (IMH, ID number 78-17).

\section{Chemical treatment}

Chlorpyrifos (CasN. 2921-88-2) and ethylene thiourea (CasN. 96-45-7), purchased from Greyhound Chromatography and Allied Chemicals and Sigma Aldrich, respectively, were stored as recommended. F1 larvae were obtained by placing adult males and females in the breeding box overnight. Spawning was triggered under light and was completed within $30 \mathrm{~min}$. The collected embryos were examined under a stereomicroscope at $2 \mathrm{hpf}$ and blastulae were selected. At $6 \mathrm{hpf}$ embryos were randomly assigned to experimental groups by placing them in separate glass Petri dishes https://joe.bioscientifica.com https://doi.org/10.1530/JOE-20-0134 (c) 2020 Society for Endocrinology Published by Bioscientifica Ltd. Printed in Great Britain 
(three plates/experimental group), with each dish containing 85 embryos in $100 \mathrm{~mL}$ of fish water containing ETU $(100 \mu \mathrm{M}), \mathrm{CPF}$ (30 or $300 \mathrm{nM}$ ), or ETU and CPF combined $(100 \mu \mathrm{M}+30 \mathrm{nM}$ or $100 \mu \mathrm{M}+300 \mathrm{nM})$. We kept them in an incubator at $28^{\circ} \mathrm{C}$, and the exposure solutions were changed daily. Larvae at $7 \mathrm{dpf}$ were anesthetized with tricaine and processed for subsequent analysis. This procedure was performed three times. In parallel, a set of 7 dpf larvae ( $n=45 /$ group per $100 \mathrm{~mL}$ ) were kept and treated until adulthood, and the exposure solutions were changed daily (180 dpf). At $10 \mathrm{dpf}$, larvae were transferred to $3.5 \mathrm{~L}$ tanks of the ZebTec toxicology stand-alone unit (Tecniplast, Italy).

F2 larvae were produced by mating with similarly exposed F1 animals ( $n=20$ males and $n=20$ females), as reported above (Supplementary Fig. 1, see section on supplementary materials given at the end of this article). At $6 \mathrm{hpf}$, embryos ( $n=85 /$ group) were exposed as above (F2-larvae) or left untreated (F2-ND larvae, $n=85 /$ group). At 7 dpf, F2 and F2-ND larvae were processed as described above. The detailed experimental plan is presented in Supplementary Fig. 1.

\section{RNA extraction and RT-qPCR analysis}

RNA from whole larvae (85 pooled larvae/group for three biological replicates) and adult livers ( $n=5$ /group), was prepared with TRIzol reagent (Invitrogen). RNA ( $1 \mu \mathrm{g}$ ) was reverse transcribed using QuantiTect Reverse Transcription Kit (Qiagen) and realtime qPCR (RT-qPCR) was performed using PowerUP SYBR Green Master Mix (Applied Biosystems with Applied Biosystem QuantStudio 7 Flex System). Primer sequences are listed inSupplementary Table 1. Data were normalized through the level of internal control tubaI (for larval samples) and actb1, for liver samples, as suggested by McCurley \& Callard 2008. The $2^{-\Delta \Delta C t}$ method was used to calculate relative expression changes.

\section{Measurement of fT3 and fT4 hormones}

$\mathrm{TH}$ levels were measured in homogenates of pooled larvae (85 larvae/group, for three biological replicates) and adult livers ( $n=3$ /group) using ELISA, according to the published protocol with minor changes (Chang et al. 2012). Briefly, larvae and adult livers were homogenized in PBS $\left(10 \mathrm{mM} \mathrm{K}_{2} \mathrm{HPO}_{4}, 100 \mathrm{mM} \mathrm{KCL}, 1 \mathrm{mM}\right.$ DTT, pH 7.4) $(1 \mathrm{~mL} / 85$ larvae, $300 \mu \mathrm{L} /$ liver $)$. After centrifugation (10 $\mathrm{min}, 5000 \boldsymbol{g}$ at $4^{\circ} \mathrm{C}$ ), the supernatants were collected and stored at $-80^{\circ} \mathrm{C}$ until $\mathrm{TH}$ levels were measured using an ELISA kit (Diametra). In total, $100 \mu \mathrm{L}$ was used for ELISA.

\section{Oil red O (ORO) staining}

Frozen livers from adult males and females ( $n=3$ /group) were subjected to ORO staining as detailed in the Supplementary materials. Briefly, liver cryosections (10 $\mu \mathrm{m}$ ) were incubated in 60\% isopropanol (5 min) and stained with ORO solution (0.5\% isopropanol for $30 \mathrm{~min}$, Sigma Aldrich) as indicated by the manufacturer. After mounting in glycerol, samples were imaged on a Zeiss AxioImager M1 microscope (20x and 63× objectives).

\section{Western blot analysis}

Proteins were prepared by lysing frozen livers ( $n=3$ /group) in RIPA buffer (50 mM Tris (pH 7.4), $150 \mathrm{mM}$ $\mathrm{NaCl}, 0.1 \%$ SDS, 0.5\% Na-deoxycholate, Nonidet P-40, protease and phosphatase inhibitor mixture (Sigma)) and analyzed by Western blotting as detailed in the Supplementary materials. The primary antibodies used were P-Foxo3a (S253), Foxo3a (75D8) and SREBP1c (28481) (Abcam). B-actin (Cell Signalling) was used to normalize data. The secondary antibodies used were anti-rabbit (G21234) and anti-mouse (G21D40) (Life Technologies).

\section{Immunohistochemical staining of thyroid follicles}

Immunostaining for $\mathrm{T}_{4}$ and thyroglobulin (TG) was performed on fixed and bleached larvae as detailed in the Supplementary materials. Staining was performed with the following antibodies: rabbit anti-T4 (1:4000, MP Biochemicals) and anti-human thyroglobulin (1:6000, Dako), respectively, as previously described (Elsalini et al. 2003, Porreca et al. 2012). Zebrafish samples were imaged on a Zeiss AxioImager M1 microscope, with $20 \times$ and $40 \times$ objectives.

\section{Statistical analysis}

The number of enrolled adults was determined by the parameters indicated by the IMH for G*Power analysis (Faul et al. 2007), as required for in vivo experiments in Italy.

Statistical analyses of the data were performed using GraphPad Prism 5 (GraphPad Software Inc). Student's t-test or ANOVA with Dunnett's post hoc correction test for multi-group comparison was performed to evaluate the 
significance of differences. RTqPCR data were expressed as the fold change of the mean \pm s.D. Probability values $<0.05$ were considered significant.

\section{Results}

\section{Early embryonic exposure to pesticides impairs TH peripheral thyroid metabolism/signaling and thyroid development}

To investigate $T_{3}$ and $T_{4}$ levels/signaling and thyroid differentiation in zebrafish larvae exposed to CPF, ETU or both ETU and CPF combined, we designed an experimental plan which included embryos generated from unexposed parents (F1-larvae) or exposed ones (F2-larvae) obtained by inter-group mating, as better specified in Supplementary Fig. 1 and the Materials and methods section. Briefly, 6 hpf embryos were exposed to ETU $100 \mu \mathrm{M}, \mathrm{CPF} 30 \mathrm{nM}$, CPF $300 \mathrm{nM}$ or both ETU and CPF combined until killing at 7 dpf (F1-larvae) or $180 \mathrm{dpf}$ (F1-adults). F2 embryos were exposed as described for F1-larvae or left untreated
(ND-F2 larvae). Doses of both compounds were chosen according to published data (Wang et al. 2017, Cao et al. 2018, Jarque et al. 2018, Yang et al. 2011), considering the need to investigate synergic/competitive activities in co-exposure conditions. No major effect was found in survival and morphology of larvae even in co-exposure conditions in either generation (data not shown).

Peripheral TH signaling is the result of the circulating level of $\mathrm{T}_{4}$, relying on thyroid function, and $\mathrm{T}_{3}$ that is mainly dependent on peripheral $\mathrm{TH}$ metabolism. We tested the l-fT4 (larval free $\mathrm{T}_{4}$ ) and l-fT3 levels using ELISA on samples prepared by whole body lysing. FT4 and fT3 levels were increased in (ETU)-, (CPF $300 \mathrm{nM}$ )- and (ETU + CPF $30 \mathrm{nM}$ )-F1 larvae (Fig. 1A and B). FT3 was also induced in larvae exposed to CPF $30 \mathrm{nM}$.

The expression of T3-targets, such as insulin growth factor binding protein 1a gene (igfbp1a) (Houbrechts et al. 2016) and carnitine palmitoyltransferase I (cpt1) (Jansen et al. 2000), was tested to verify the effects of fT3 increase. Both were induced in (CPF $30 \mathrm{nM})$ - and (ETU + CPF 300 nM)-F1 larvae (Fig. 1C and D, respectively). The increase was statistically significant only for igfbp1a in larvae
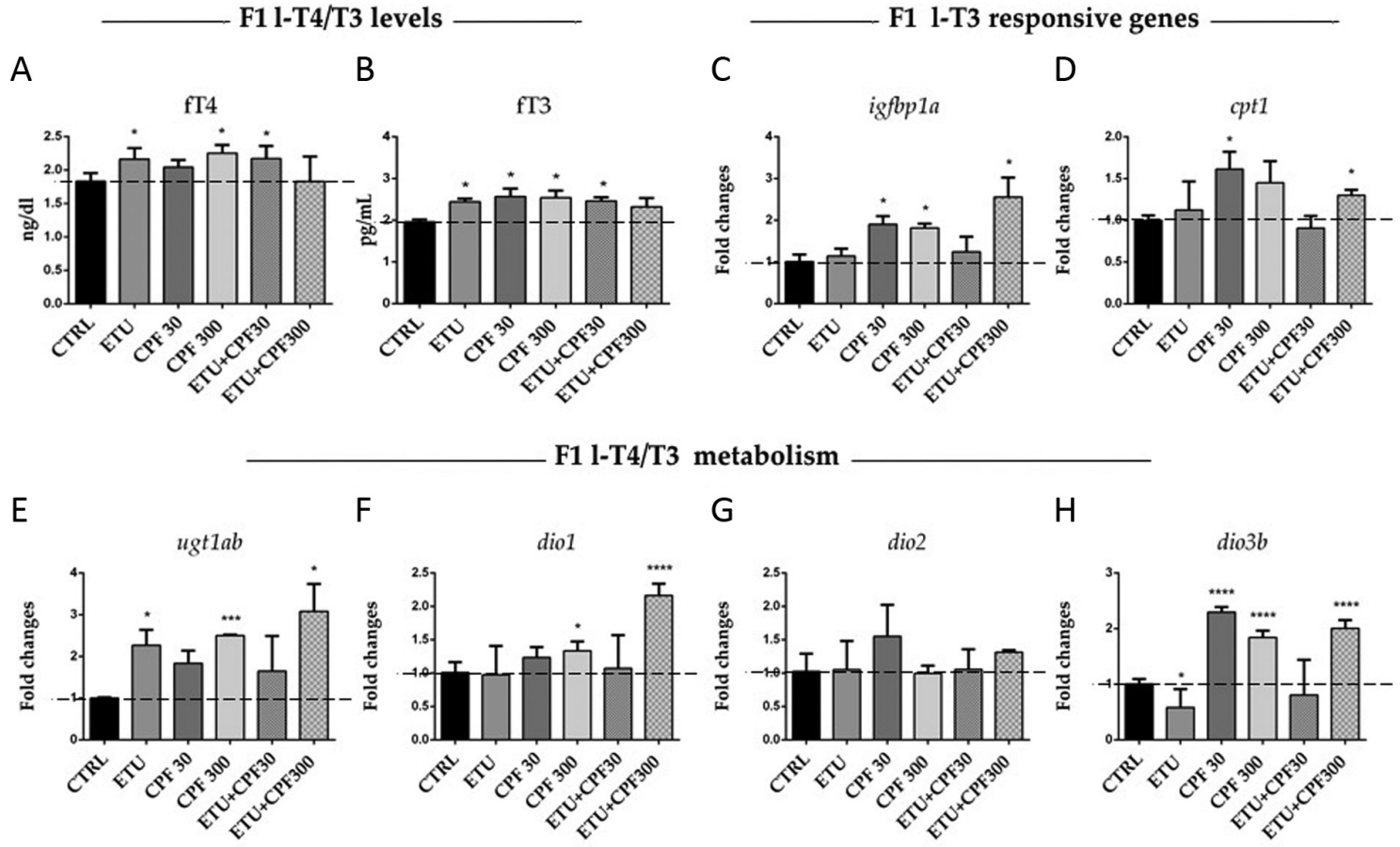

\section{Figure 1}

Larval fT4- and fT3-level/metabolism and signaling is altered in F1 larvae exposed to CPF, ETU or both ETU and CPF combined. (A and B) L-fT4 and I-fT3 levels were determined by ELISA in F1 zebrafish larvae. (C and D) Levels of igfbp1a and cpt1 mRNAs (I-T3 responsive genes) and (E-H) ugt1ab, dio1, dio2, dio3b transcripts (I-T4/T3 metabolism) were assayed by RTqPCR, as reported in the Materials and methods section. Experiments were conducted on larvae exposed to pesticides from $6 \mathrm{hpf}$ to the time of killing (7 dfp) or left untreated (CTRL). RTqPCR tests were performed on pools of 85 larvae from three independent experiments. Data analysis was conducted as described in the Materials and methods section. Data are reported as fold change values calculated as a ratio between average relative gene expression in treated and control larvae, after normalization on tubal mRNA. Mean and S.D. are reported. ${ }^{*} P<0.05, * \star P<0.01, * \star * P<0.001, * \star * \star P<0.0001$. 
exposed to CPF $300 \mathrm{nM}$. Subsequently, we analyzed the expression of the genes involved in $\mathrm{TH}$ metabolism, such as iodothyronine deiodinase 2 (dio 2 - converting $\mathrm{T}_{4}$ in $\mathrm{T}_{3}$ ), iodothyronine deiodinase 1 and $3 \mathrm{~b}$ (dio1, dio3b, inactivating $\mathrm{T}_{3}$ ) and UDP glucuronosyltransferase 1 family a, b (ugt1ab, involved in $\mathrm{T}_{3}$ inactivation via dio1). As expected, these last three transcripts were induced with $\mathrm{T}_{3}$ increment. Concordantly, we found the induction of their mRNAs in (CPF-300 nM) and (ETU + CPF $300 \mathrm{nM})$ $\mathrm{F} 1$ larvae. dio3b mRNA was increased in larvae exposed to CPF $30 \mathrm{nM}$, whereas it was reduced in ETU-F1 larvae. Its regulation was the opposite of ugt1ab only in (ETU)-F1 larvae. No major change in dio2 transcript was found (Fig. 1E, F, G and H). The levels of transthyretin (ttr, $\mathrm{T}_{4}$ transporter) and thyroid receptor alpha a/beta (thraa/b) transcripts were evaluated. thraa and thrb mRNAs were both induced in (CPF $30 \mathrm{nM}$ )- and (ETU+CPF $300 \mathrm{nM}$ )F1 samples, whereas the first was also induced in (CPF $300 \mathrm{nM}$ )-larvae. $t$ tr RNAs showed a pathway of regulation similar to dio3b (Supplementary Fig. 2D-F). Overall, the data suggested that early life exposure to CPF, ETU or both ETU and CPF combined altered thyroid status in zebrafish larvae.

We then investigated thyroid development/ function. We determined the number of thyroid follicles by immunohistochemistry (IHC) using an antibody against $\mathrm{T}_{4}$ (Fig. $2 \mathrm{~A}, \mathrm{~B}, \mathrm{C}, \mathrm{D}, \mathrm{E}, \mathrm{F}$ and $\mathrm{G}$ ) or against thyroglobulin (TG, Supplementary Fig. 2A). $\mathrm{T}_{4}$ staining revealed the reduction of the follicle number in all the conditions compared to control, except for

Anti-T4 IHC F1 larvae
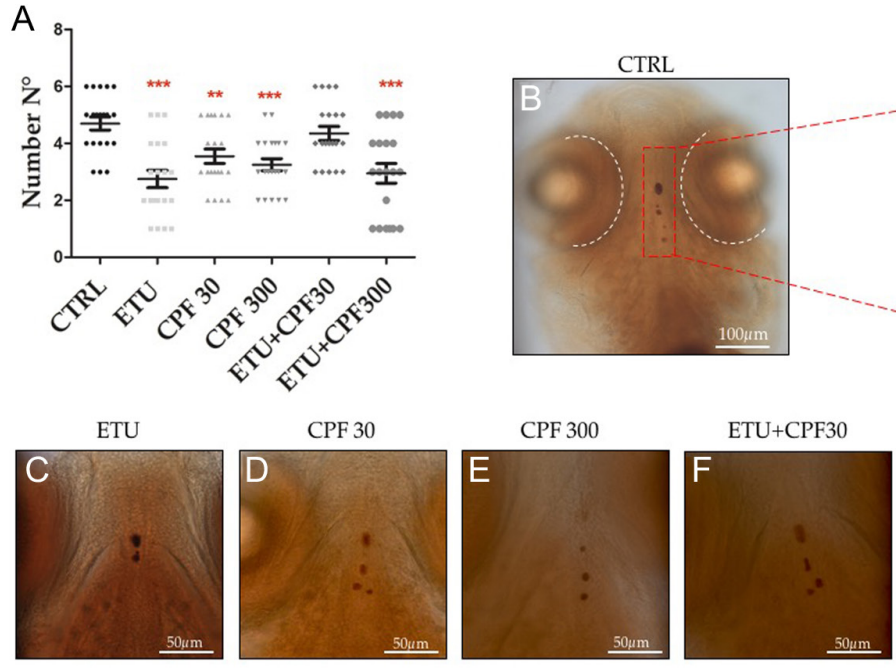

Thyroid follicles specific markers
$\mathrm{H}$

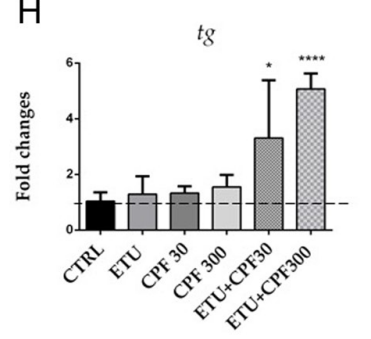

I
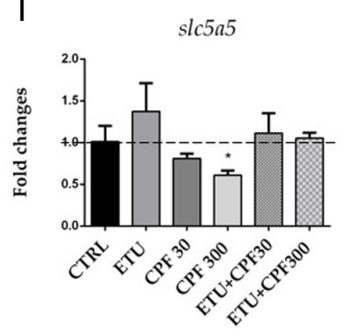

$J$

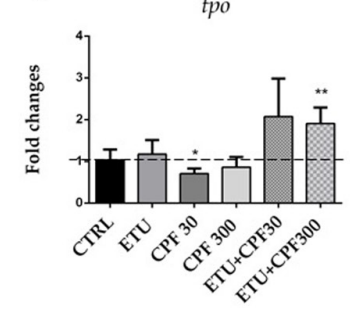

HPT-axis
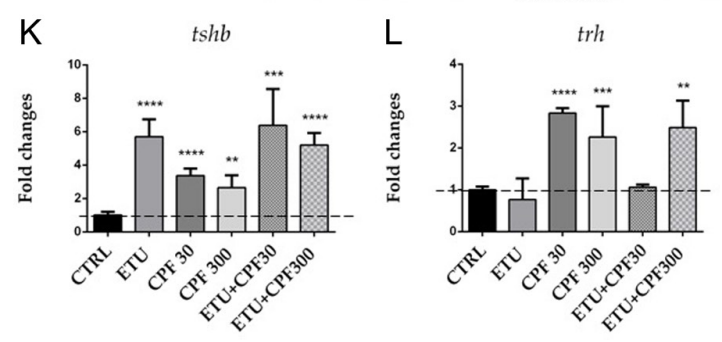
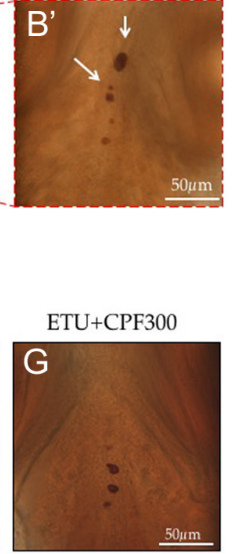

Figure 2

Thyroid development and HPT-axis gene expression is damaged in F1 larvae exposed to pesticides. (A) Number of thyroid follicles in control (CTRL) and exposed (from $6 \mathrm{hpf}$ to $7 \mathrm{dpf}$ ) F1 larvae, stained by immunohistochemistry (IHC) using an antibody against $\mathrm{T}_{4}$, as reported in the Materials and methods section. 20 larvae/group collected from three independent experiments were used. Each data point is a single larva. Mean and S.D. are reported, $* P<0.05$. (B and $\mathrm{B}^{\prime}$ )

Representative image of thyroid follicles in control F1 zebrafish larvae in a ventral view (B, 20x magnification, $B^{\prime}, 40 \times$ magnification). (C-G) Representative images of thyroid follicles in $\mathrm{F} 1$ larvae exposed to pesticides (40× magnification). $(\mathrm{H}-\mathrm{J})$ Transcripts of $\operatorname{tg}$, s/c5a5, tpo (thyroid follicles-specific markers); ( $\mathrm{K}$ and $\mathrm{L}$ ) tshb and trh (HPT-axis) were assayed by RTqPCR on pools of 85 larvae from three independent experiments. Data analysis was conducted as described in the Materials and methods section. Data are reported as fold change values calculated as the ratio between average relative gene expression in treated and control larvae, after normalization on tubal mRNA. Mean and S.D. are reported.

$\star P<0.05, * * P<0.01, * * * P<0.001, * * * * P<0.0001$. A full color version of this figure is available at https://doi.org/10.1530/JOE-20-0134. 
(ETU + CPF 30 nM)-F1 samples (Fig. 2A). TG staining confirmed the result (Supplementary Fig. 2A). Thyroglobulin $(t g)$ and thyroid peroxidase (tpo) transcripts were induced in larvae exposed to ETU + CPF $300 \mathrm{nM}$. tg mRNA was also positively regulated in (ETU + CPF $30 \mathrm{nM})$ larvae (Fig. $2 \mathrm{H}$ and $\mathrm{J}$ ), whereas (Na)-iodide symporter (slc5a5) mRNA was reduced in larvae exposed to CPF $300 \mathrm{nM}$ (Fig. 2I). The expression of pax8 and $n k x 2.4 b$, transcriptional regulators of these thyroid-specific genes, was impaired. pax8 mRNA increased in (CPF $30 \mathrm{nM}$ )and (CPF $300 \mathrm{nM}$ )-F1 larvae while $n k x 2.4 b$ mRNA was decreased in all exposure conditions, except for (ETU)-F1 larvae (Supplementary Fig. 2B and C). Finally, we evaluated the levels of $t s h b$ and trh transcripts, enhanced in the pituitary and hypothalamus, of hypothyroid animals. We observed an increase of tshb mRNA in all treatments (Fig. 2K), whereas trh mRNA was increased only in (CPF $30 \mathrm{nM})-$, (CPF $300 \mathrm{nM})$ - and (ETU + CPF 300 nM)-F1 samples (Fig. 2L).

The group of regulated mRNAs specific to the HPTaxis in F1 larvae emphasized the impact of pesticide exposure, in that thyroid development and HPT function was damaged.

\section{Parental exposure results in impairment of body larval T3-level/signaling and thyroid development/function in the offspring even without further exposure}

We investigated the effects of parental exposure on the offspring obtained via F1 adult inter-group mating and further exposed (F2)- or untreated (ND F2)-larvae, as detailed in Supplementary Fig. 1.

L-fT4 levels were increased in (CPF 30 nM)-, (CPF 300 nM)- and (ETU+CPF 300 nM) F2-larvae (Fig. 3A). Although not statistically significant, the increase was also evident in (CPF 300 nM)- and (ETU+CPF 300 nM) ND-F2 larvae. L-fT4 and l-fT3 levels were decreased in (ETU +CPF $30 \mathrm{nM}$ )F2 larvae and only the first was even strongly reduced in the ND-groups (Fig. 3B). L-fT3 was reduced in (ETU +CPF $30 \mathrm{nM}$ )-F2 larvae and showed an increasing trend in all the other groups of exposure. This result was corroborated by
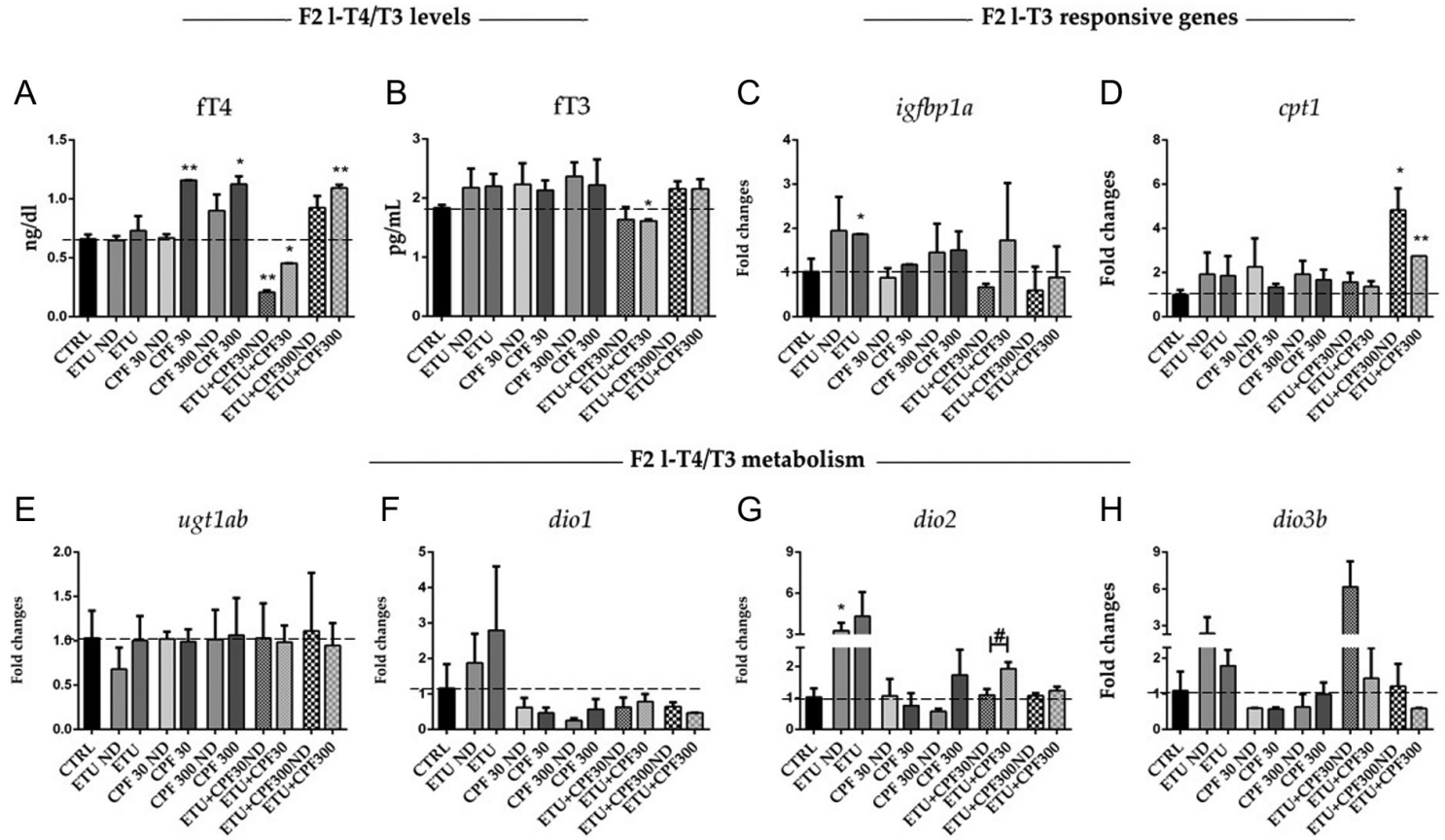

\section{Figure 3}

Larval T4/T3-levels and expression of genes involved in IT3-levels/responsive gene/thyroid metabolism in F2 zebrafish larvae exposed or not exposed to pesticides. (A and B) L-fT4 and I-fT3 levels were detected by ELISA in zebrafish larvae from exposed parents and further exposed from $6 \mathrm{hpf}$ to $7 \mathrm{dpf}$ (F2-larvae) or not exposed (ND F2-larvae). (C and D) mRNAs of I-T3-regulated transcripts (igfbp1a and cpt1) and (E-H) enzymes involved in TH metabolism (ugt1ab, dio1, dio2, dio3b) were assayed using RTqPCR in F2- and ND F2-larvae as reported in the Materials and methods section. RTqPCR tests were performed on pools of 85 larvae from three independent experiments. Data analysis was conducted as described in the Materials and methods section. Data are reported as fold change values calculated as a ratio between average relative gene expression in treated and control larvae, after normalization on tubal mRNA. Mean and S.D. are reported as $* P<0.05, * * P<0.01, * \star * P<0.001, * \star * * P<0.0001$. 
the expression profile of T3-responsive genes, igfbp $1 a$ and cpt1. igfbp1a mRNA level was found to be increased in a statistically significant manner in (ETU)-F2 larvae, although only a trend towards induction was observed in (ETU ND), (CPF300 ND and CPF300) and (ETU+CPF30)-F2 samples (Fig. 3C). cpt1 mRNA was augmented in (ETU + CPF $300 \mathrm{nM})$ F2 larvae, and this increase was even stronger in ND-larvae. An increasing trend in cpt1 mRNA was also observed in the other exposure conditions (Fig. 3D).

Expression of dio2 was increased in (ETU ND)-larvae (Fig. 3G). A trend toward an increase was evident in (ETU)-, $(\mathrm{CPF} 300 \mathrm{nM})$ - and (ETU + CPF 30n M)-F2 groups, but was only statistically significant in (ETU ND)-larvae (Fig. 3G). No modification was observed for ugt1ab gene (Fig. 3E), whereas a trend toward dio1 mRNA reduction was found in all samples, except for (ETU)- and (ETU ND)-F2 larvae, in which it was regulated in the opposite manner (Fig. 3F). Although not statistically significant, dio3b mRNA was enhanced in both (ETU)- and (ETU+CPF $30 \mathrm{nM}$ )exposure groups (Fig. 3H). thrb mRNA was induced in (ETU) and (CPF-30 nM) F2 larvae and in the respective ND-F2 samples (Supplementary Fig. 3E). thraa transcript was increased only in (CPF $300 \mathrm{~nm}$ )-F2 larvae and in (ETU $\mathrm{ND}$ )- and (CPF $300 \mathrm{nM} \mathrm{ND)-F2} \mathrm{samples.}$

The thyroid follicles were counted upon staining with an antibody against $\mathrm{T}_{4}$ (Fig. 4A) and TG (Supplementary Fig. 3A). We noted a reduction in the number of follicles in (ETU)-, (ETU+CPF $30 \mathrm{nM})$ - and (ETU + CPF $300 \mathrm{nM})$ F2 larvae (Fig. 4A and H, I, J, L) vs control (Fig. 4B). Interestingly, the number of follicles was restored in ND-F2 larvae in the last two conditions (Fig. 4C, D, E, F and G). $\mathrm{tg}$, scl5a5 and tpo mRNAs were induced in (ETU)-samples and only scl5a5 in (ETU ND)-F2 larvae (Fig. 4M, N and O). scl5a5 mRNA was increased in (ETU + CPF $30 \mathrm{nM} \mathrm{ND)-F2}$ larvae and also showed a trend toward induction in the co-exposed samples as tpo mRNA (Fig. $4 \mathrm{~N}$ and O). Unlike the F1 larvae, we found a different expression of pax 8 and $n k \times 2.4 b$ genes. Indeed, both were inhibited in (CPF $30 \mathrm{nM}$ ) and (ETU +CPF $300 \mathrm{nM})$-F2 samples. pax 8 increased in (ETU ND), while $n k x 2.4 b$ was upregulated in (ETU)-, (ETU + CPF30)-, (CPF 300 ND)-, and (ETU+CPF 300ND)F2 larvae (Supplementary Fig. 3B and C). pax8 mRNA was positively regulated in (ETU ND)- and (ETU)-F2 larvae, though this was not statistically significant in the second group (Supplementary Fig. 3B). $n k x 2.4 b$ mRNA increased in the (ETU)- and (ETU + CPF $30 \mathrm{nM}$ )-F2 group (Supplementary Fig. 3C). The level of tshb mRNA showed a trend toward upregulation (Fig. 4P), whereas trh mRNA increased in (ETU)-, (ETU ND)-, (ETU + CPF $30 \mathrm{nM}$ )- and (ETU + CPF 300 nM ND)-F2.
The data in F2 larvae confirmed the effects of pesticide exposure on $\mathrm{TH}$ metabolism/signaling, demonstrating that parental exposure was sufficient to promote them in different conditions.

\section{Hepatic $\mathrm{T}_{3}$-level/signaling in $\mathrm{F} 1$-adult livers is damaged by early embryonic exposure to pesticides}

$\mathrm{T}_{3}$ regulates metabolic processes and its altered level/ signaling during early life damages metabolic health during adulthood (Mullur et al. 2014). Therefore, we evaluated the effects of exposure on liver metabolic health in adult (180 dpf) F1-males $(n=15)$ and females $(n=15)$. No striking phenotypic abnormality, including in reproductive ability, was found in three different matings, nor was any difference found in mortality rate. An increase in body weight and length at the time of killing (180 dpf) was observed in (ETU + CPF $300 \mathrm{nM}$ )F1 females. In the same exposure group, body weight was increased in the F1-males and in (ETU+CPF $30 \mathrm{nM}$ ) animals (Fig. 5A and B).

Hepatic lipid accumulation was confirmed by ORO of liver sections prepared from cryopreserved samples. No major effect of ETU was found in females ( $n=3$, Fig. $5 \mathrm{C}$ and $\mathrm{D}$ ) or males ( $n=3$, Fig. 5I and J), whereas a dosedependent activity of CPF was found in both sexes (Fig. 5E and $\mathrm{F}$ females; Fig. $5 \mathrm{~K}$ and $\mathrm{L}$ males), although less severe in males. Representative images are shown in Fig. 5. Lipid accumulation was restricted to some areas of the liver in (CPF $300 \mathrm{nM}$ )- and (ETU+CPF $30 \mathrm{nM}$ )-males (Fig. 5L and $\mathrm{M}$ ). Milder sex-dependent differences were detected in co-exposed fish: ETU alleviated CPF $300 \mathrm{nM}$ activity in both sexes (Fig. $5 \mathrm{H}$ and $\mathrm{N}$ ) and CPF $30 \mathrm{nM}$ only in females (Fig. 5E).

We determined the hepatic (h)-fT4 and h-fT3 levels using ELISA ( $n=3$ males and females/groups). Their profiles were partially overlapping in males: fT4 increased by exposure to CPF $300 \mathrm{nM}$ and ETU+CPF $30 \mathrm{nM}$, and fT3 increased by exposure to ETU and ETU +CPF $30 \mathrm{nM}$ (Fig. 6I and J). The overlap was not found in females because fT4 was increased in animals exposed to CPF $30 \mathrm{nM}$ and ETU+CPF $300 \mathrm{nM}$, whereas fT3 was not regulated in either condition. Its reduction was evident in (ETU +CPF $30 \mathrm{nM}$ )-females (Fig. 6A and B). Although slight and often not statistically significant, the increase in h-fT3 (Fig. 6J) was concordant with the upregulation of igfbp $1 a$ and cpt 1 mRNAs in male livers $(n=5$, Fig. $6 \mathrm{~K}$ and L). In females $(n=5)$, the expression of igfbp $1 a$ increased only in (ETU)- and (ETU + CPF $300 \mathrm{nM}$ )-livers (Fig. 6C), with a concordant increase in the fT3 level only in the 

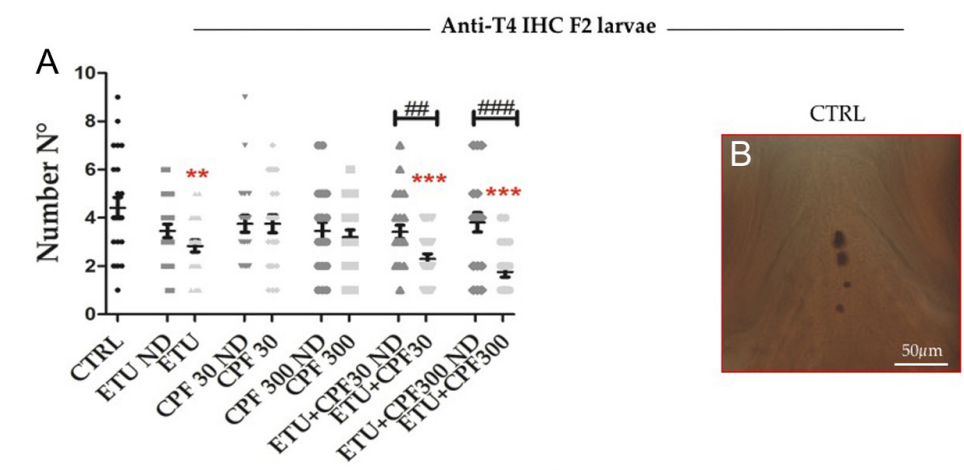
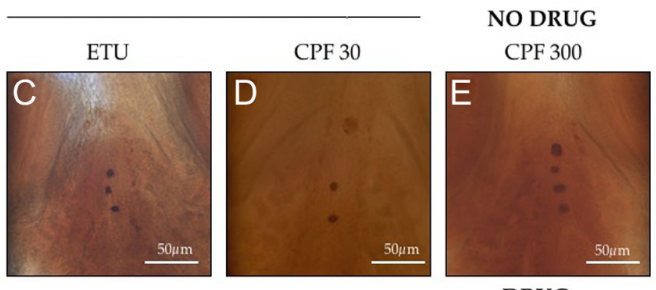

DRUG
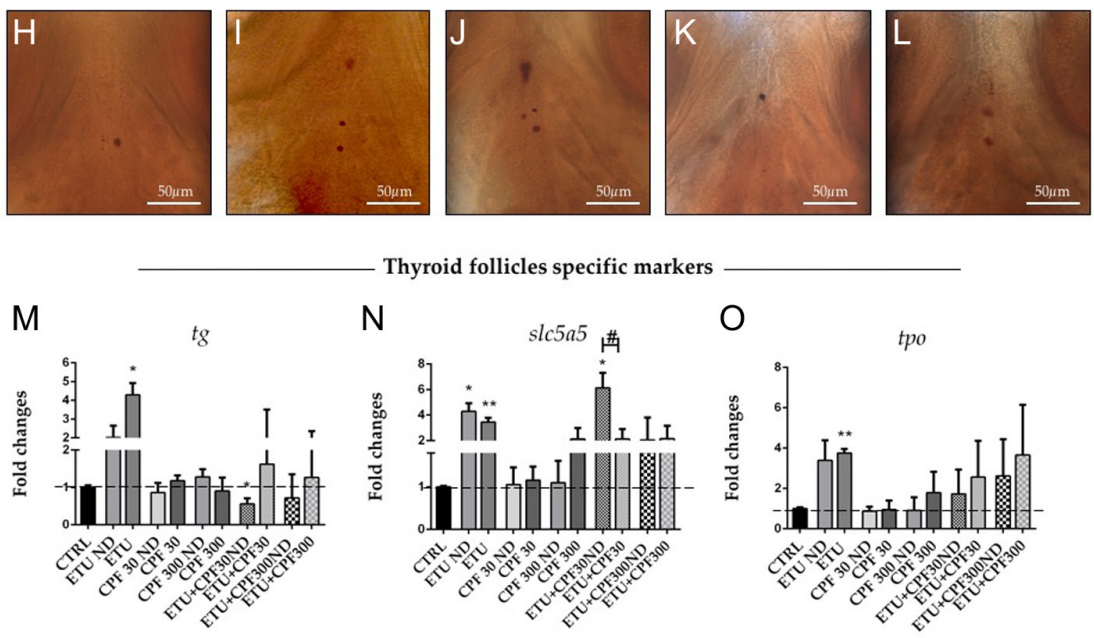

Thyroid follicles specific marker

N

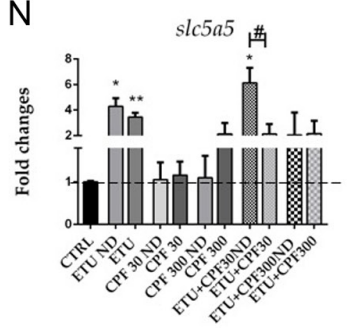

o

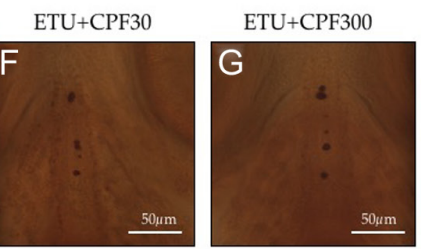

HPT-axis
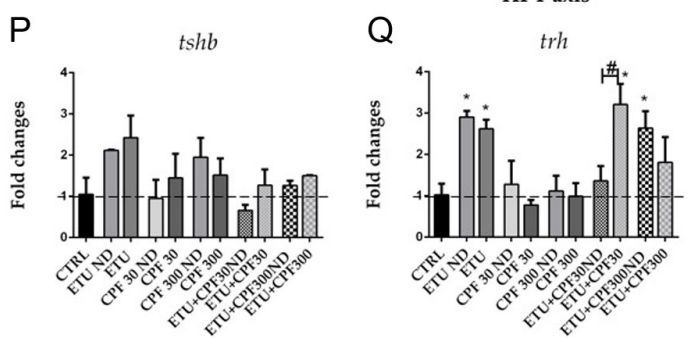

tpo

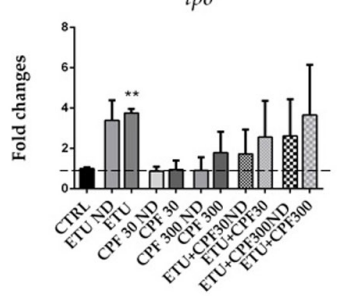

\section{Figure 4}

Thyroid development and HPT-axis gene expression are damaged in F2 zebrafish larvae. (A) The graph represents the number of thyroid follicles in control (CTRL) and exposed larvae left untreated (ND F2) or exposed (F2) from $6 \mathrm{hpf}$ to $7 \mathrm{dpf}$ (Supplementary Fig. 1), as reported in Fig. 2. Staining was performed with an antibody against $\mathrm{T}_{4}$ on 20 larvae/group from three independent experiments. Each data point is a single larva. Mean and S.D. are reported. (B) Representative images of thyroid follicles in control F2 larvae ( $B$, 40× magnification). (C-L) Representative images (40x magnification) of thyroid follicles in F2 larvae left unexposed (ND, C-G) or exposed (H-L). A significant difference in the control group is indicated by $* * P<0.01, * * * P<0.001$, whereas a significant difference in the ND-group is reported

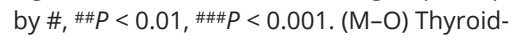
specific mRNAs (tg, s/c5a5 and tpo), (P and Q) pituitary- and hypothalamus-specific (tshb and trh, respectively) were assayed by RTqPCR. Pools of 85 larvae/group were left untreated (ND) or exposed to pesticides, as described in the Materials and methods section. RTqPCR tests were performed separately on pools of 85 larvae from three independent experiments. Data analysis was conducted as described in the Materials and methods section. Data are reported as fold change values calculated as a ratio between average relative gene expression in treated and control adults, after normalization on tubal mRNA. Mean and S.D. are reported. A significant difference in the control group is indicated by $*, * P<0.05, * * P<0.01$, whereas a significant difference in the ND-group is indicated by \#, $\# P<0.05$. A full color version of this figure is available at https://doi.org/10.1530/JOE-20-0134. former group (Fig. 6B). Furthermore, it was inhibited in (CPF $300 \mathrm{nM})$ - and (ETU + CPF $30 \mathrm{nM}$ )-female livers, whereas cpt1 mRNA was always found to be reduced (Fig. 6D). We verified the expression of genes involved in 'de novo lipogenesis'. acc mRNA was increased in all conditions in females, although this was not statistically significant in (CPF $300 \mathrm{nM})$ and (ETU + CPF $300 \mathrm{nM}$ ) females. fasn transcription was inhibited at both doses in CPF and in (ETU + CPF 30 nM)-livers
(Supplementary Fig. 4C). Both genes were induced only in (ETU)-male livers and reduced in (CPF $30 \mathrm{nM}$ )-samples (Supplementary Fig. 4K). Furthermore, fasn was reduced in co-exposed males of both groups.

As hepatic $\beta$-oxidation is directly targeted by $T_{3}$ (Sinha et al. 2018), we assessed the expression of genes involved in $\mathrm{T}_{3}$ metabolism and transport. dio3b transcript was induced in (ETU)- and (CPF-300 nM)-female livers and decreased in (ETU + CPF $300 \mathrm{nM}$ )-samples (Fig. 6H). 


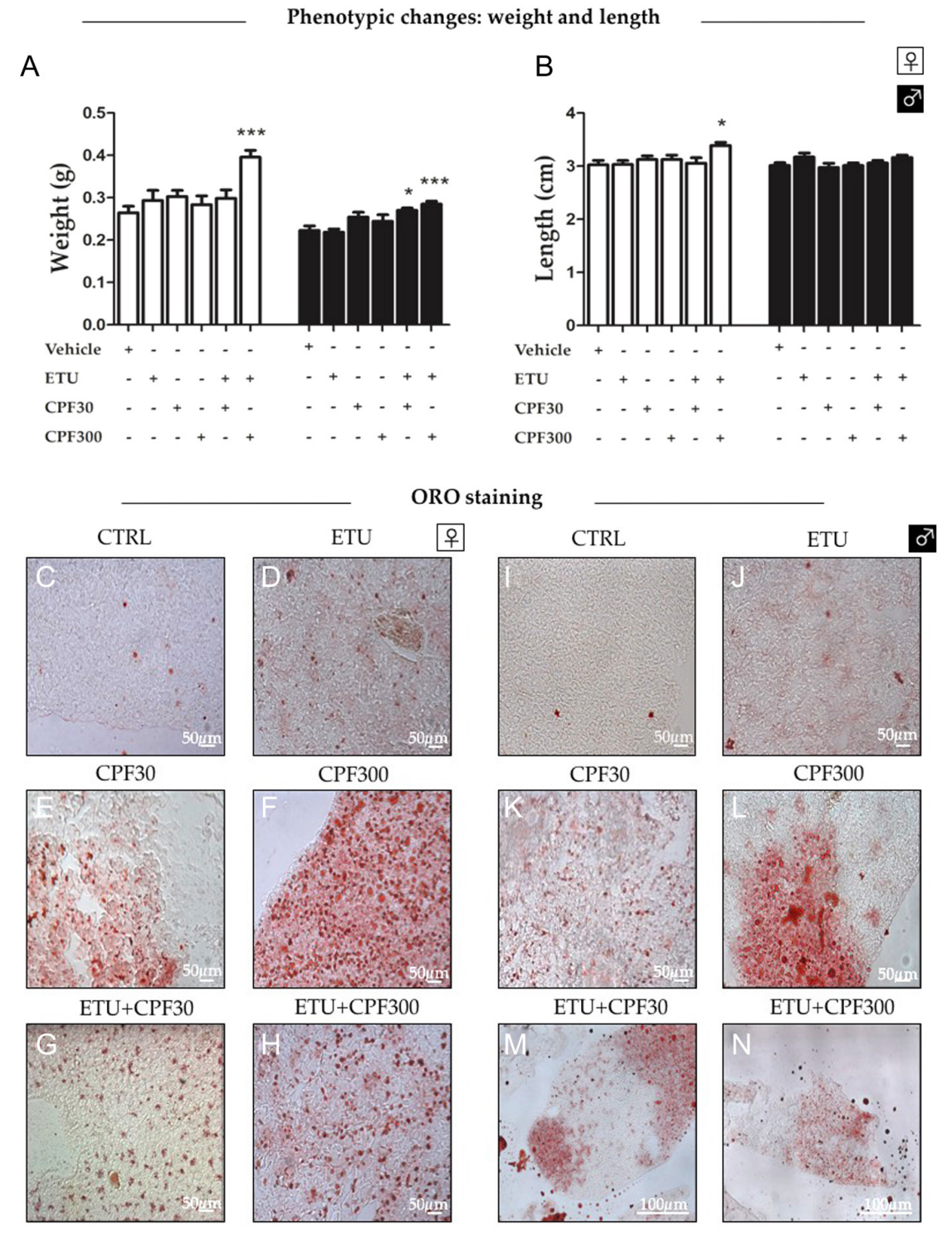

\section{Figure 5}

Embryonic exposure to pesticides induces liver steatosis in a sex- and exposure-dependent manner. (A and B) Weight gain and length were measured in control (CTRL) and exposed zebrafish, from $6 \mathrm{hpf}$ to the $180 \mathrm{dpf}$, males $(n=15)$ and females $(n=15)$. Mean and S.D. are reported. A significant difference from the control group is indicated by $* P<0.05, * * * P<0.001$. Lipid accumulation in the liver was confirmed by ORO staining of sections obtained from samples stored in the OCT of adult females ( $\mathrm{C}-\mathrm{H})$ and males $(\mathrm{I}-\mathrm{N})$, as reported in the $\mathrm{M} \& \mathrm{M}$ section. Staining was performed on at least three animals/groups. 20x and $63 \times$ Magnification images are shown. A full color version of this figure is available at https:// doi.org/10.1530/JOE-20-0134.
Concordantly, dio2 mRNA was inhibited in the first two conditions (Fig. 6G). ugt1ab mRNA was upregulated in (CPF-30 nM)- and (ETU + CPF $30 \mathrm{nM}$ )-females (Fig. 6E), whereas dio1 transcript was inhibited in exposed females (Fig. 6F). In males, hepatic dio2 and dio3b mRNAs were always increased (Fig. $6 \mathrm{O}$ and $\mathrm{P}$, respectively) and dio1 expression was augmented in all exposure groups, except for (CPF $30 \mathrm{nM}$ )-male livers (Fig. 6N). ugt1ab was inhibited in (CPF $30 \mathrm{nM}$ )-male liver in a statistically significant manner, while a decrease was observed in the other groups with the exception of (CPF $300 \mathrm{nM}$ ) livers (Fig. 6M). ttr and thrb transcripts were similarly reduced in all the exposed female livers (Supplementary Fig. 4G and $\mathrm{H})$, whereas this was significant only for (CPF $30 \mathrm{nM}$ )and (ETU + CPF $300 \mathrm{nM}$ ) livers in males (Supplementary Fig. $4 \mathrm{O}$ and $\mathrm{P})$.
This data suggests that $T_{3}$ signaling in male livers increases, probably in order to protect against the effects of CPF exposure.

\section{Hepatic PPARa/Foxo3a pathway is damaged by early embryonic exposure to pesticides}

The discordance between $T_{3}$ levels and cpt1 mRNA, especially in female livers, suggested damage to other signaling pathways. To get new insights, we analyzed with the JASPAR tool (Fornes et al. 2020) a sequence of 5000 bp upstream of the zebrafish cpt1a gene to retrieve the binding sites for its putative transcriptional regulators. We found binding sites for THRB/PPAR/NR1I3, SREBFs and FOXO3 (Fig. 7A). As PPAR $\alpha$ is the major regulator of cpt1 gene expression, 
A

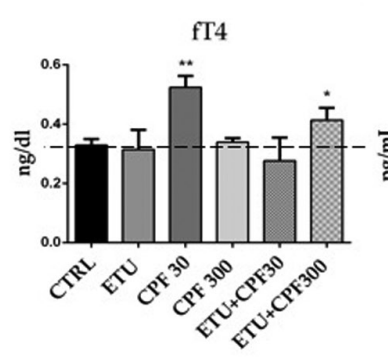

B

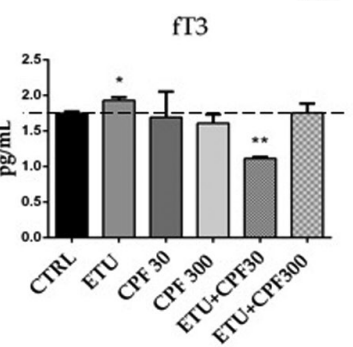

우 1

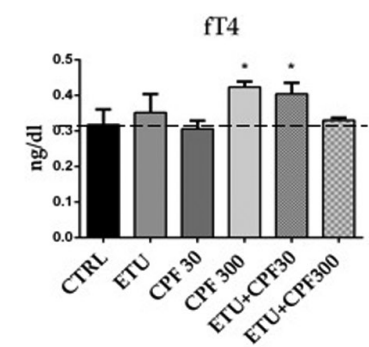

J

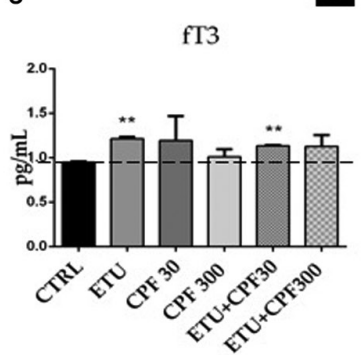

$h-T 3$ responsive genes

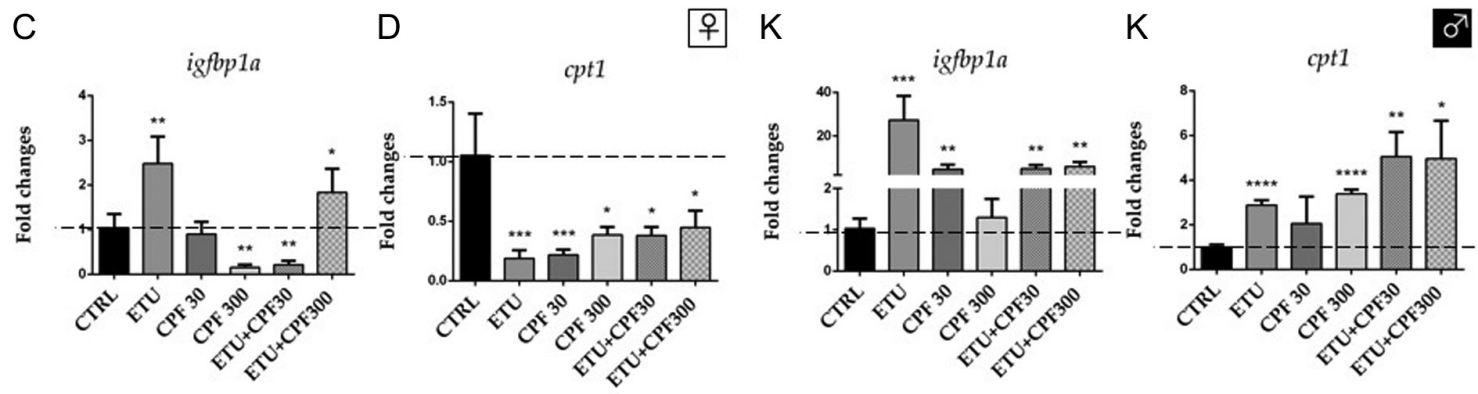

C

శ)

\section{h-T4/T3 metabolism}
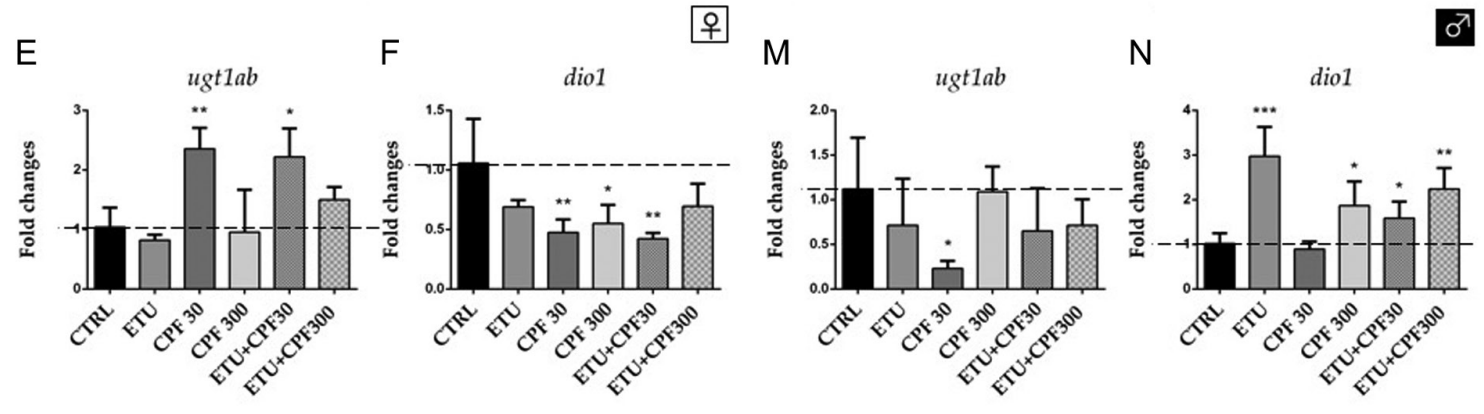

G

$\mathrm{H}$

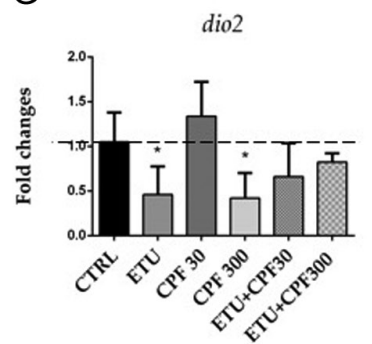

H dio3b

O
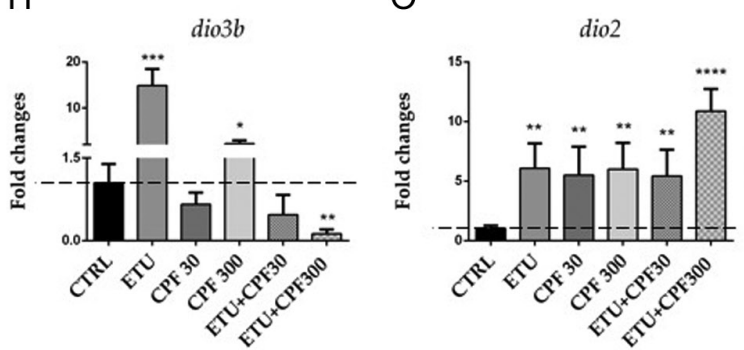

P

dio3b

Figure 6

Sex-dependent modulation of hT4/T3-level and regulation of TH metabolic enzymes/T3-regulated transcripts in livers of adult zebrafish exposed to pesticides. H-fT4 and h-fT3 levels were determined by ELISA in females $(n=3 ; \mathrm{A}, \mathrm{B})$ and males $(n=3 ; \mathrm{I}, \mathrm{J})$, exposed from $6 \mathrm{hpf}$ to $180 \mathrm{dpf}$, and prepared as described in the Materials and methods section. (C, D) Female and (K, L) male mRNA level of h-T3 responsive genes igfbp1a and cpt1 was assayed by RTqPCR, as reported in the Materials and methods section. (E-H) Female and (M-P) male mRNAs of TH metabolizing enzymes, ugt1ab, dio1, dio2, dio3b, in livers of adult fishes. RTqPCR tests were performed on livers of five males and five females/groups. Data analysis was conducted as described in the Materials and methods section. Data are reported as fold change values calculated as a ratio between average relative gene expression in treated and control adults, after normalization on actb1 mRNA. Mean and S.D. are reported. Significant difference from the control group is indicated by $* P<0.05$, $\star \star P<0.01, * * * P<0.001, * * * * P<0.0001$ 


\section{Journal of

M Colella, V Nittoli,

Cpt1a Promoter

A

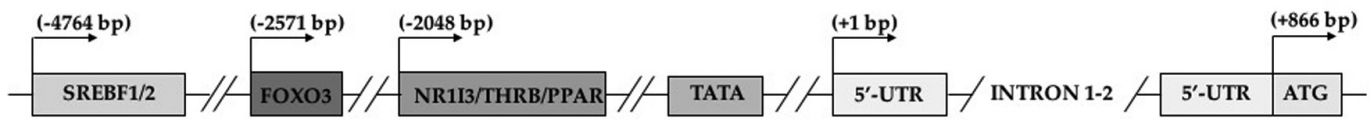

Hepatic-metabolism

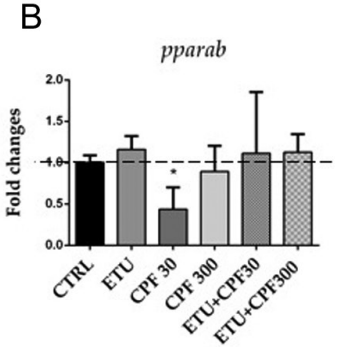

C

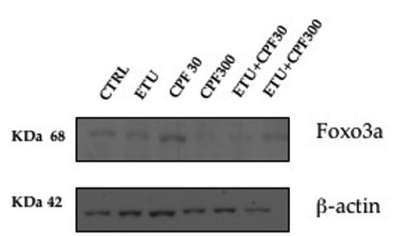

E

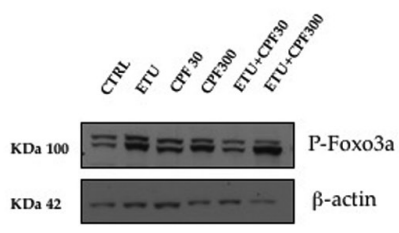

D

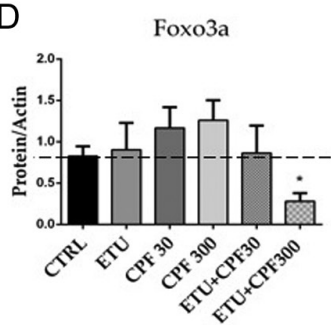

F

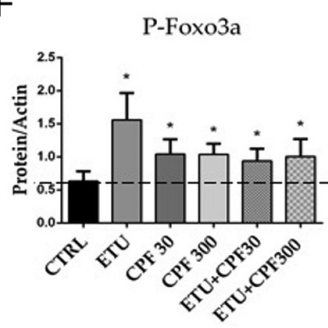

G

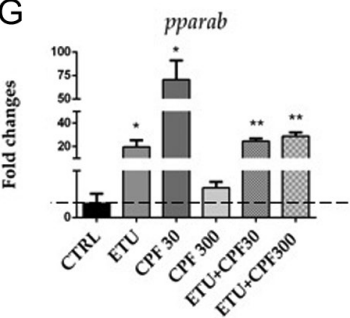

$\mathrm{H}$

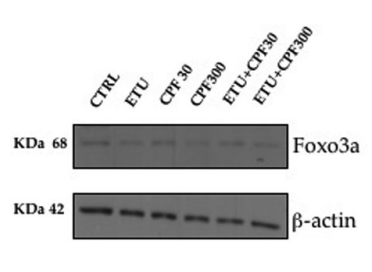

I Foxo3a

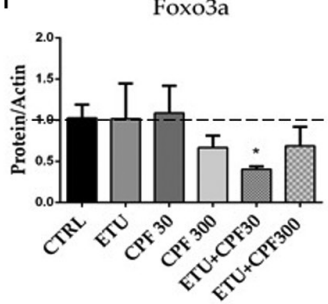

J

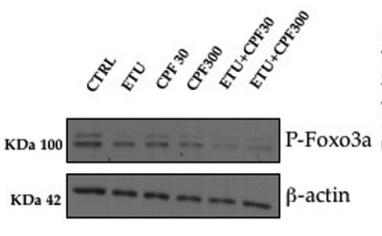

K

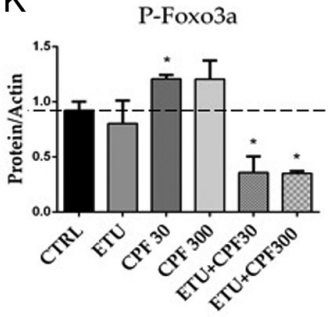

\section{Figure 7}

Pesticides deregulate the PPAR $\alpha$ /Foxo3a axis in zebrafish liver. (A) Schematic representation of the zebrafish cpt1a promoter (5000 bp upstream of the cpt1 gene, ENSEMBL, transcript ID ENSDART00000145375.5) as found with bioinformatics analysis conducted with JASPAR. Levels of pparab transcripts in female $(n=5 ; \mathrm{B})$ and male ( $n=5 ; \mathrm{G}$ ) livers of fish exposed to pesticides from 6 hpf to $180 \mathrm{dpf}$. Data analysis was conducted, as described in the Materials and methods section. Data are reported as fold change values calculated as a ratio between average relative gene expression in treated and control adults, after normalization on actb1 mRNA. Mean and S.D. are reported. A significant difference from the control group is indicated by * $P<0.05$,

$\star \star P<0.01$. Representative images of Western blotting analyses of Foxo3a and P-Foxo3a (Ser253) conducted in females $(n=3$; C, E) and males ( $n=3$; H, J). Samples were processed as described in the Materials and methods section. Each line represents a single fish. Semiquantitative analysis of the Western blotting results was conducted upon normalization on $\beta$-actin level and densitometric analyses. Statistical analysis is shown for females (D, F) and males $(\mathrm{I}, \mathrm{K})$. Data analysis was conducted as described in the Materials and methods section. Mean and S.D. are reported. A significant difference from the control group is indicated by $* P<0.05$.

we determined its level by RTqPCR. Indeed, the PPAR $\alpha$ antibody did not work in zebrafish (Schlaepfer \& Joshi 2020). ppar alpha (pparab) mRNA was inhibited in (CPF $30 \mathrm{nM}$ )-female livers (Fig. 7B), whereas its expression was strongly induced in all the exposed males (Fig. 7G), except for (CPF $300 \mathrm{nM}$ )-male livers. We also assessed the level of fasn and acc mRNAs, because it was regulated by thrb and PPAR $\gamma$. Interestingly, the increase of acc
mRNA in females (Supplementary Fig. 4C) could not be explained by ppar gamma mRNA (pparg) and SRBF1 protein (Supplementary Fig. 4A, D and E, respectively) regulation: the first was always inhibited and the second was induced only in (ETU + CPF 300 nM)-female livers. In males, fasn and acc mRNAs increased only in (ETU)livers (Supplementary Fig. 4J and K) even though the pparg mRNA increase was not statistically significant in 
these samples (Supplementary Fig. 4I). No major effect was detected for SRBF1 protein in male livers.

The Foxo3 pathway has a role in cpt1 mRNA regulation (Shao et al. 2016). Since the phosphorylation by Akt of Foxo3 at Ser S253 (P-Foxo3a) has been shown to inactivate the pathway by promoting protein export from the nucleus, we analyzed the levels of P-Foxo3a and Foxo3a by Western blotting. Although the cellular content of Foxo3a was diminished only in (ETU + CPF 300 nM) female livers (Fig. 7C and D), P-Foxo3a levels were increased in all the conditions in this sex (Fig. 7E and F). P-Foxo3a in males was induced in (CPF $30 \mathrm{nM}$ )-livers (Fig. 7J and $\mathrm{K}$ ). Concordant with the increase in lipid accumulation detected by ORO staining, a trend toward its increase was also evident in (CPF $300 \mathrm{nM}$ )-male livers.

Finally, we evaluated the hepatic expression of TNF alpha, which is considered a negative factor in hepatic steatosis (Copaci et al. 2006). We observed a major increase in TNF alpha mRNA in all conditions in females (Supplementary Fig. 5A) but this was not statistically significant in (CPF $300 \mathrm{nM}$ ) and (ETU) and (ETU + CPF 300 nM)-male livers (Supplementary Fig. 5B).

Overall, the data suggested that males were protected from hepatic steatosis because of the hyperthyroid status of the liver concomitant with the activation of the PPAR/Foxo3a pathway.

\section{Discussion}

The mechanisms which regulate thyroid development/ function and the processes controlled locally by THs are conserved in vertebrates. Several rodent studies provide evidence that both are targets of thyroid-hormonedisrupting chemicals (THDCs) such as CPF and ETU (Leemans et al. 2019). The imbalance of TH signaling is a factor contributing to several diseases, including hepatic lipid dysmetabolism, regardless of whether it is the result of the alteration of thyroid function and/or of peripheral TH metabolism. By simultaneous analysis of thyroid gland morphology/development, TH levels/signaling and HPTaxis activity, we report evidence that adaptive processes are established to ensure the correct level of $\mathrm{T}_{3}$ is maintained following exposure to low doses of CPF, ETU or both ETU and CPF combined, from early developmental stages. The slight increase in 1-fT4 and 1-fT3 might be the result of such a process, as suggested by the upregulation of several thyroid-specific transcripts and tsh $b$ mRNAs. The detected increase in l-fT3 and the levels of deiodinase transcripts in whole larvae can depend on the need to stabilize the $\mathrm{T}_{3}$ levels up to the tissue-specific demand (Table 1). This does not imply that hypothyroidism can be promoted in specific organs, as shown by tshb mRNA induction in the pituitary (Table 1).

Table 1 Summary of results of F1-larvae and F2-larvae.

\begin{tabular}{|c|c|c|c|c|}
\hline & Anterior pituitary & Thyroid & Whole body & Thyroid function/whole \\
\hline \multicolumn{5}{|c|}{ L-fT4, L-fT3, dio2, dio3b, igfbp1a, cpt1 } \\
\hline F1-Larvae & & & & \\
\hline ETU & tshb $\uparrow^{d}$ & $\downarrow,{ }^{c} \operatorname{tg}(-)$, nis $\uparrow$, tpo $(-)$ & $\begin{array}{l}\text { L-fT4 } \uparrow,{ }^{a} \text { L-fT3 } \uparrow,{ }^{a} \text { dio } 2(-), \operatorname{dio} 3 b \downarrow^{,}{ }^{a} \\
\quad \text { igfbp1a (-), cpt1 (-) }\end{array}$ & $\downarrow / \uparrow$ \\
\hline CPF 30 & tshb $\uparrow^{d}$ & $\downarrow^{\mathrm{b}} \operatorname{tg}(-)$, nis $\downarrow$, tpo $\downarrow^{\mathrm{a}}$ & $\begin{array}{l}\text { L-fT4 } \uparrow, ~ L-f T 3 ~ \uparrow, \text { a dio } 2 \uparrow, \operatorname{dio} 3 b \uparrow{ }^{d} \\
\text { igfbp } 1 a \uparrow,^{\text {a }} \text { cpt } 1 \uparrow^{a}\end{array}$ & $\downarrow / \uparrow$ \\
\hline CPF 300 & $t s h b \uparrow b$ & $\downarrow^{\prime}{ }^{c} \operatorname{tg}(-)$, nis $\downarrow,^{\text {a }}$ tpo (-) & $\begin{array}{l}\text { L-fT4 } \uparrow, \text { a L-fT3 } \uparrow, \text { a } \operatorname{dio} 2(-), \operatorname{dio} 3 b \uparrow,{ }^{d} \\
\text { igfbp } 1 a \uparrow,^{a} \text { cpt1 } \uparrow\end{array}$ & $\downarrow / \uparrow$ \\
\hline $\mathrm{ETU}+\mathrm{CPF} 30$ & $\operatorname{tsh} b \uparrow c$ & $(-), \operatorname{tg} \uparrow,{ }^{a}$ nis $(-)$, tpo $\uparrow$ & $\begin{array}{l}\text { L-fT4 } \uparrow, \text { a L-fT3 } \uparrow, \text { a dio2 }(-), \text { dio3b } \\
(-), \text { igfbp1a }(-), \operatorname{cpt} 1(-)\end{array}$ & $\downarrow / \uparrow$ \\
\hline ETU + CPF 300 & $t s h b \uparrow^{d}$ & $\downarrow,{ }^{c} \operatorname{tg} \uparrow,{ }^{d}$ nis $(-)$, tpo $\uparrow^{b}$ & $\begin{array}{l}\text { L-fT4 }(-), \text { L-fT3 } \uparrow, \operatorname{dio} 2(-), \operatorname{dio} 3 b \uparrow,{ }^{d} \\
\quad \text { igfbp1a }{ }^{\text {a }} \text { cpt1 } \uparrow^{\mathrm{a}}\end{array}$ & $\downarrow / \uparrow$ \\
\hline \multicolumn{5}{|l|}{ F2-Larvae DRUG } \\
\hline ETU & $\operatorname{tsh} b \uparrow$ & $\downarrow_{1}, \mathrm{~b} \operatorname{tg} \uparrow,{ }^{a}$ nis $\uparrow, \mathrm{b}$ tpo $\uparrow^{\mathrm{b}}$ & $\begin{array}{l}\text { L-fT4 (-), L-fT3 } \uparrow, \text { dio } 2 \uparrow, \operatorname{dio} 3 b \uparrow, \\
\text { igfbp } 1 a \uparrow,^{a} \text { cpt } 1 \uparrow\end{array}$ & $\downarrow / \uparrow$ \\
\hline CPF 30 & $\operatorname{tsh} b \uparrow$ & $\downarrow, \operatorname{tg}(-)$, nis $(-)$, tpo (-) & $\begin{array}{l}\text { L-fT4 } \uparrow, \mathrm{b} \text { L-fT3 } \uparrow, \operatorname{dio} 2(-), \operatorname{dio} 3 b \downarrow \\
\text { igfbp1a }(-), \operatorname{cpt1}(-)\end{array}$ & $\downarrow / \uparrow$ \\
\hline CPF 300 & $\operatorname{tsh} b \uparrow$ & $\downarrow, \operatorname{tg}(-)$, nis $\uparrow$, tpo $\uparrow$ & $\begin{array}{l}\text { L-fT4 } \uparrow, \text { a L-fT3 } \uparrow, \operatorname{dio} 2 \uparrow, \operatorname{dio} 3 b(-), \\
\text { igfbp1a } 1 \text { cpt1 } \uparrow\end{array}$ & $\downarrow / \uparrow$ \\
\hline $\mathrm{ETU}+\mathrm{CPF} 30$ & $\operatorname{tsh} b \uparrow$ & $\downarrow, c \operatorname{tg}(-)$, nis $\uparrow$, tpo $\uparrow$ & $\begin{array}{l}\text { L-fT4 } \downarrow \text {, a L-fT3 } \downarrow \text {, a dio } 2 \uparrow, \operatorname{dio} 3 b(-), \\
\text { igfbp } 1 a \uparrow, c p t 1(-)\end{array}$ & $\downarrow / \uparrow$ \\
\hline ETU + CPF 300 & $\operatorname{tsh} b \uparrow$ & $\downarrow, c \operatorname{tg}(-)$, nis $\uparrow$, tpo $\uparrow$ & $\begin{array}{l}\text { L-fT4 } \uparrow, \mathrm{b} \text { L-fT3 } \uparrow, \text { dio2 }(-), \operatorname{dio} 3 b \downarrow \text {, } \\
\text { igfbp1a (-), cpt1 } \uparrow^{\mathrm{b}}\end{array}$ & $\downarrow / \uparrow$ \\
\hline
\end{tabular}

Schematic representation of the results for different treatments. Symbol: $\uparrow$, upregulation; $\downarrow$, downregulation; (-), no change. Significant difference from the control group is indicated by $\mathrm{a} P<0.05 ; \mathrm{b} P<0.01 ; \mathrm{c} P<0.001 ; \mathrm{d} P<0.0001$.

\begin{tabular}{|c|c|}
\hline $\begin{array}{l}\text { https://joe.bioscientifica.com } \\
\text { https://doi.org/10.1530/JOE-20-0134 }\end{array}$ & $\begin{array}{l}\text { (c) } 2020 \text { Society for Endocrinology } \\
\text { Published by Bioscientifica Ltd. }\end{array}$ \\
\hline
\end{tabular}
Printed in Great Britain 
The timing of thyroid developmental steps in zebrafish has been established using temporal tracking of the stages impaired by pesticides. Our analyses at 7 dpf showed no major effect on thyroid specification and migration, until the complete formation of the first and single follicle, which normally concluded in 72 hpf (Alt et al. 2006). THs are supplied by the yolk until that time. The detection of a reduced number of follicles suggests that major effects could involve growth and proliferation. Although we cannot distinguish between a lack of follicle development and their death, their numeric reduction implies limited $\mathrm{T}_{4}$ production that is not sufficient to counteract the decrement of the TH maternal level due to the depletion of the yolk. The observed maintenance relies on the activation of the feedback loop that stimulates $\mathrm{T}_{4}$ production by the remaining follicles. We observed a reduction in the number of follicles in F1 and F2 larvae. tshb mRNA induction may intervene in compensating for the alteration of follicle formation at late stages. Indeed, TSH regulates thyroid growth and differentiation, but it is not involved in organogenesis or cell migration (Marians et al. 2002, Postiglione et al. 2002). Interestingly, tshr morphants showed a reduction in the size and number of follicles, downregulation of differentiation markers (such as slc5a5 and to a lesser extent $t g$ ), and reduced expression of thyroid transcription factors in zebrafish (Opitz et al. 2011). Thus, tshb transcript induction may participate in the establishment of an an efficient thyroid late differentiation, independently from the raising of TH levels (Table 1). Although we can suggest that early exposure to pesticides might damage late thyroid differentiation and peripheral TH metabolism/signaling, future studies are needed to analyze this feature in depth.

Because of its external development, zebrafish permits larval damage due to direct embryonic exposure to be investigated. The data reported here demonstrate that parental exposure worsens the embryonic effects of pesticides in terms of reduction of follicle number and the activation of the feedback loop, which is less effective in F2 vs F1 (Table 1). Indeed, the increase in 1-fT4 and 1-fT3 is less evident in F2 larvae and is restricted to a few conditions, such as in the (ETU +CPF $30 \mathrm{nM}$ )-group. Differences could also be detected in the regulation of dio3b induced in ETU-F2 larvae and inhibited in F1-samples (Table 1). The small increase in $t s h b$, which regulates the expression of the thyroid-specific genes such as scl5a5, suggests that other pathways might be involved, such as NF-kB. We have proposed it as a regulator of $\mathrm{scl} 5 a 5$ expression in mice exposed to p-dioxin and have shown that CPF reduces p65 nuclear level in rat follicular cells (Reale et al. 2018, 2019). The results found in F2-larvae provide evidence that parental exposure might itself cause the reduction of the number of follicles and hypothyroidism, although we cannot distinguish between the impairment of the $\mathrm{TH}$ reserve in the yolk or germline epigenetic changes. This point should be specifically addressed.

Different human and rodent studies pointed out that the embryonic impairment of TH levels might modulate organ development and activity in adulthood (Colborn et al. 1993, Zoeller 2010, Gutleb et al. 2016, Porreca et al. 2017). Here, we focus on liver metabolic activity in adults, because it is a major target of T3-signaling. The data suggest a sex- and exposure-dependent promotion of liver steatosis, which is summarized in Table 2. CPF and ETU differ in such activity, with CPF being more effective than ETU. Both compounds exert a milder effect in male livers, which are protected by the increase in hepatic T3 levels/ signaling, resulting in the accumulation of $c p t 1$ mRNA. In steatotic female livers, the balance between the transcripts of the T3-activating enzymes (dio2) and inactivating ones (dio1 and dio3b) is indicative of its reduction (Fig. 6). We found a significant discrepancy between the sex-dependent differences in $\mathrm{T}_{3}$ level/signaling and an opposite trend in regulation of cpt1 mRNA (Table 2). This emphasizes the possible involvement of other pathways, such as PPAR $\alpha$ and Foxo3a, both shown as regulators of cpt1 expression in mammals but not in zebrafish (Asaoka et al. 2013). The increase of P-Foxo3a in female liver agrees with the cpt1 mRNA downregulation reported in rodents. Indeed, P-Foxo3a cytoplasmic retention resembles the mouse loss-of-function mutation (Tzivion et al. 2011) because its transcriptional activity is inhibited. Concordantly P-Foxo3a is less phosphorylated in exposed males and a strong induction of PPAR $\alpha$ was also described (Radenne et al. 2008). This is relevant because thrb, whose expression is reduced in females and is weakly expressed in males, acts in synergy with PPAR $\alpha$ in regulating gene expression (Table 2). The $\mathrm{T}_{3}$ increase in males might enhance PPAR $\alpha /$ Thrb complex formation and activity (Videla et al. 2016). PPAR $\alpha$ regulation might play a double role because it could inhibit AKT/Foxo3a phosphorylation, as reported in kidney (Chung et al. 2012). Indeed, we report an increase in PPAR $\alpha$ and reduced Foxo3a phosphorylation in males. Furthermore, Foxos can interact with several nuclear receptors including TRs and PPARs and, within the complex, the activity of both proteins can be differently modulated (van der Vos \& Coffer 2008). Finally, $\mathrm{T}_{3}$ and https://joe.bioscientifica.com

https://doi.org/10.1530/JOE-20-0134 (c) 2020 Society for Endocrinology Published by Bioscientifica Ltd.
Printed in Great Britain 
Table 2 Summary of the results of F1-adult female and male.

\begin{tabular}{|c|c|c|c|c|}
\hline & Lipid accumulation & $\begin{array}{l}\text { Hepatic } T 4 / \Gamma 3 \text { levels and } \mathrm{TH} \\
\text { responsive transcripts }\end{array}$ & $\begin{array}{l}\text { Pathways involved in hepatic } \\
\text { steatosis }\end{array}$ & $\begin{array}{l}\text { Hepatic thyroid status/hepatic } \\
\text { lipid accumulation }\end{array}$ \\
\hline Sample name & ORO staining & $\mathrm{H}-\mathrm{fT} 4, \mathrm{H}-\mathrm{fT} 3$, igfbp $1 a, c p t 1$ & thrb, pparab, P-Foxo3a, tnfa & $\begin{array}{l}\uparrow \text { or } \downarrow / \text { slight, severe or moderate } \\
\text { steatosis }\end{array}$ \\
\hline \multicolumn{5}{|l|}{ Fl-Adult Female } \\
\hline ETU & Slight effect & $\begin{array}{l}\mathrm{H}-\mathrm{fT} 4(-), \mathrm{H}-\mathrm{fT} 3 \uparrow,{ }^{\mathrm{a}} \text { igfbp } 1 a \\
\uparrow, \mathrm{b} \text { cpt1 } \downarrow^{\mathrm{c}}\end{array}$ & $\begin{array}{l}\text { thrb } \downarrow, c \text { pparab (-), P-Foxo3a } \\
\quad \uparrow,{ }^{\text {a }} \text { tnfa } \uparrow^{a}\end{array}$ & $\uparrow /$ slight steatosis \\
\hline CPF 30 & Severe effect & $\begin{array}{l}\mathrm{H}-\mathrm{fT} 4 \uparrow, \mathrm{b} \mathrm{H}-\mathrm{fT} 3(-), \text { igfbp } 1 a \\
(-), \text { cpt1 } \downarrow^{c}\end{array}$ & $\begin{array}{l}\text { thrb } \downarrow \text {, b pparab } \downarrow \text {, a P-Foxo3a } \\
\uparrow, \text { a tnfa } \uparrow \text { a }\end{array}$ & $\downarrow /$ severe steatosis \\
\hline CPF 300 & Severe effect & $\begin{array}{l}\mathrm{H}-\mathrm{fT} 4(-), \mathrm{H}-\mathrm{fT} 3(-), \text { igfbp } 1 a \\
\quad \downarrow^{\mathrm{b}} \text { cpt1 } \downarrow^{\mathrm{a}}\end{array}$ & $\begin{array}{l}\text { thrb } \downarrow \text {, b pparab (-), P-Foxo3a } \\
\quad \uparrow, \text { a tnfa } \uparrow\end{array}$ & $\downarrow /$ severe steatosis \\
\hline $\mathrm{ETU}+\mathrm{CPF} 30$ & Moderate effect & $\begin{array}{l}\mathrm{H}-\mathrm{fT} 4(-), \mathrm{H}-\mathrm{fT} 3 \downarrow^{\mathrm{b}} \text { igfbp } 1 a \\
\downarrow^{\mathrm{b}} \text { cpt1 } \downarrow^{\mathrm{a}}\end{array}$ & $\begin{array}{l}\text { thrb } \downarrow \text {, }, \text { pparab (-), P-Foxo3a } \\
\uparrow,{ }^{a} \text { tnfa } \uparrow \mathrm{b}\end{array}$ & $\downarrow /$ moderate steatosis \\
\hline $\mathrm{ETU}+\mathrm{CPF} 300$ & Moderate effect & $\begin{array}{l}\mathrm{H}-\mathrm{fT} 4 \uparrow,{ }^{\mathrm{a}} \mathrm{H}-\mathrm{fT} 3(-), \text { igfbp } 1 a \\
\uparrow,{ }^{a} \text { cpt1 } \downarrow^{\mathrm{a}}\end{array}$ & $\begin{array}{l}\text { thrb } \downarrow_{,}{ }^{c} \text { pparab (-), P-Foxo3a } \\
\uparrow,{ }^{a} \text { tnfa } \uparrow^{a}\end{array}$ & $\uparrow /$ moderate steatosis \\
\hline \multicolumn{5}{|l|}{ Fl-Adult Male } \\
\hline ETU & Slight effect & $\begin{array}{l}\mathrm{H}-\mathrm{fT} 4(-), \mathrm{H}-\mathrm{fT} 3 \uparrow, \mathrm{b} \text { igfbp } 1 a \\
\uparrow_{,}{ }^{c} \text { cpt1 } \uparrow^{\mathrm{d}}\end{array}$ & $\begin{array}{l}\text { thrb }(-), \text { pparab } \uparrow, \text { a P-Foxo3a } \\
(-) \text {, tnfa } \downarrow\end{array}$ & $\uparrow /$ slight steatosis \\
\hline CPF 30 & Moderate effect & $\begin{array}{l}\mathrm{H}-\mathrm{fT} 4(-), \mathrm{H}-\mathrm{fT} 3 \uparrow, \text { igfbp } 1 a \\
\uparrow, \mathrm{b} \text { cpt1 } \uparrow\end{array}$ & $\begin{array}{l}\text { thrb } \downarrow_{1}{ }^{c} \text { pparab } \uparrow, \text { a P-Foxo3a } \uparrow,{ }^{a} \\
\text { tnfa } \uparrow \mathrm{b}\end{array}$ & $\uparrow /$ moderate steatosis \\
\hline CPF 300 & Moderate effect & $\begin{array}{l}\mathrm{H}-\mathrm{fT} 4 \uparrow, \text { a } \mathrm{H}-\mathrm{fT} 3(-), \text { igfbp1a } \\
(-), \text { cpt1 } \uparrow^{\mathrm{d}}\end{array}$ & $\begin{array}{l}\text { thrb }(-), \text { pparab } \uparrow, \text { P-Foxo3a } \uparrow, \\
\text { tnfa } \downarrow^{\mathrm{b}}\end{array}$ & $\uparrow /$ moderate steatosis \\
\hline $\mathrm{ETU}+\mathrm{CPF} 30$ & Moderate effect & $\begin{array}{l}\mathrm{H}-\Gamma \Gamma 4 \uparrow \uparrow^{\mathrm{a}} \mathrm{H}-\mathrm{fT} 3 \uparrow,^{\mathrm{b}} \text { igfbp } 1 a \\
\uparrow, \mathrm{b} c p t 1 \uparrow^{\mathrm{b}}\end{array}$ & $\begin{array}{l}\text { thrb } \downarrow, \mathrm{b} \text { pparab } \uparrow, \mathrm{b} \text { P-Foxo3a } \\
\quad \downarrow, \text { a tnfa } \downarrow\end{array}$ & $\uparrow /$ moderate steatosis \\
\hline ETU + CPF 300 & Moderate effect & $\begin{array}{l}\mathrm{H}-\mathrm{fT} 4(-), \mathrm{H}-\mathrm{fT} 3 \uparrow, \text { igfbp } 1 a \\
\uparrow, \mathrm{b} \text { cpt1 } \uparrow^{\mathrm{a}}\end{array}$ & 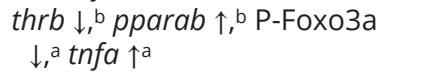 & $\uparrow /$ moderate steatosis \\
\hline
\end{tabular}

Schematic representation of the results for different treatments. Symbol: $\uparrow$, upregulation; $\downarrow$, downregulation; (-), no change. A significant difference from the control group is indicated by $a P<0.05$; $b P<0.01$; $c P<0.001$; $d P<0$.

Foxo3a signaling might be involved in the sex-dependent regulation of TNF $\alpha$ mRNA (Table 2) because $\mathrm{T}_{3}$ could reduce the production of pro-inflammatory cytokines in the liver (Taki-Eldin et al. 2012) and the retention of Foxo3a in the nuclei of male hepatocytes could contribute (Xia \& Zhu 2013). The role of other pathways, such as estrogen signaling, could be explored (Marlatt et al. 2012).

In conclusion, hyperthyroidism presents at larval stages, as a result of alteration in thyroid development/function and peripheral TH metabolism/signaling and results in the impairment of $\beta$-oxidation and 'de novo lipogenesis at larval stages (Supplementary Figs 2G, H and 3G, H) and in adult livers (Supplementary Fig. 4B, C, J and K). Mechanistically, sex-dependent regulation of lipid metabolism is the result of the organ/tissue-specific crosstalk between $\mathrm{T}_{3}$ signaling and other pathways, such as Foxo3a and PPARs, and is involved in the preservation of hepatic health in mammals. Here, we report evidence of their activity in zebrafish adult livers, which emphasizes the vast potential of zebrafish in investigating pathways involved in complex metabolic diseases such as hepatic steatosis.

\section{Supplementary materials}

This is linked to the online version of the paper at https://doi.org/10.1530/ JOE-20-0134.

\section{Declaration of interest}

The authors declare that there is no conflict of interest that could be perceived as prejudicing the impartiality of the research reported.

\section{Funding}

This work was supported by: The Italian Workers' Compensation Authority (grant no 12010), Sensor Regione Campania (grant no 23), Goodwater Regione Campania (POR Campania FESR 2014/2020 O.S. 1.1 Az. 1.1.3 E 1.1.4-CUP B63D18000150007) and POR FESR 2014-2020-Projects (RARE PLATNET, SATIN and COEPICA) Regione Campania.

\section{Author contribution statement}

A C, P I and N V involved in conceptualization. C M, N V and P A performed methodology. C M and $\mathrm{N} V$ involved in software technique. $\mathrm{C} \mathrm{M}$ and $\mathrm{N} \mathrm{V}$ helped in validation. $M M, C M$ and $N$ V involved in formal analysis. P I, $R C, R F, R N A, R L$ and A F performed investigation. C M, N V and $M M$ involved in data curation. $C M, N V$ and $C A$ involved in writing and drafted the original manuscript. de $\mathrm{FM}, \mathrm{M} \mathrm{M}$, and $\mathrm{A} C$ involved in writing, review and editing. $\mathrm{M} \mathrm{M}$ and $\mathrm{A} C$ involved in supervision. $\mathrm{A} C$ performed project administration. $M M$ and $A C$ involved in funding acquisition. All authors have read and agreed to the published version of the manuscript. $M \mathrm{M}$ and C A contributed equally as last authors to this work.

\section{Acknowledgement}

The authors thank Dr Antonia Giacco for the careful reading of the manuscript. https://joe.bioscientifica.com https://doi.org/10.1530/JOE-20-0134 (c) 2020 Society for Endocrinology Published by Bioscientifica Ltd. Printed in Great Britain 


\section{References}

Alt B, Reibe S, Feitosa NM, Elsalini OA, Wendl T \& Rohr KB 2006 Analysis of origin and growth of the thyroid gland in Zebrafish. Developmental Dynamics 235 1872-1883. (https://doi.org/10.1002/dvdy.20831)

Asaoka Y, Terai S, Sakaida I \& Nishina H 2013 The expanding role of fish models in understanding non-alcoholic fatty liver disease. Disease Models and Mechanisms 6 905-914. (https://doi.org/10.1242/ dmm.011981)

Axelstad M, Boberg J, Nellemann C, Kiersgaard M, Jacobsen PR, Christiansen S, Hougaard KS \& Hass U 2011 Exposure to the widely used fungicide mancozeb causes thyroid hormone disruption in rat dams but no behavioral effects in the offspring. Toxicological Sciences 120 439-446. (https://doi.org/10.1093/toxsci/kfr006)

Belpoggi F, Soffritti M, Guarino M, Lambertini L, Cevolani D \& Maltoni C 2002 Results of long-term experimental studies on the carcinogenicity of ethylene-bis-dithiocarbamate (mancozeb) in rats. Annals of the New York Academy of Sciences 982 123-136. (https://doi. org/10.1111/j.1749-6632.2002.tb04928.x)

Cao F, Souders 2nd CL, Li P, Pang S, Qiu L \& Martyniuk CJ 2018 Biological impacts of organophosphates chlorpyrifos and diazinon on development, mitochondrial bioenergetics, and locomotor activity in zebrafish (Danio rerio). Neurotoxicology and Teratology 70 18-27. (https://doi.org/10.1016/j.ntt.2018.10.001)

Chang J, Wang M, Gui W, Zhao Y, Yu L \& Zhu G 2012 Changes in thyroid hormone levels during zebrafish development. Zoological Science 29 181-184. (https://doi.org/10.2108/zsj.29.181)

Chhabra RS, Eustis S, Haseman JK, Kurtz PJ \& Carlton BD 1992 Comparative carcinogenicity of ethylene thiourea with or without perinatal exposure in rats and mice. Fundamental and Applied Toxicology 18 405-417. (https://doi.org/10.1016/02720590(92)90139-9)

Chung HW, Lim JH, Kim MY, Shin SJ, Chung S, Choi BS, Kim HW, Kim YS, Park CW \& Chang YS 2012 High-fat diet-induced renal cell apoptosis and oxidative stress in spontaneously hypertensive rat are ameliorated by fenofibrate through the PPARalpha-FoxO3a-PGC1alpha pathway. Nephrology, Dialysis, Transplantation 27 2213-2225. (https://doi.org/10.1093/ndt/gfr613)

Clift D, Richendrfer H, Thorn RJ, Colwill RM \& Creton R 2014 Highthroughput analysis of behavior in zebrafish larvae: effects of feeding. Zebrafish 11 455-461. (https://doi.org/10.1089/zeb.2014.0989)

Colborn T, vom Saal FS \& Soto AM 1993 Developmental effects of endocrine-disrupting chemicals in wildlife and humans. Environmental Health Perspectives 101 378-384. (https://doi. org/10.1289/ehp.93101378)

Colella M, Cuomo D, Giacco A, Mallardo M, De Felice M \& Ambrosino C 2020 Thyroid hormones and functional ovarian reserve: systemic vs. peripheral dysfunctions. Journal of Clinical Medicine 9 1679. (https:// doi.org/10.3390/jcm9061679)

Copaci I, Micu L \& Voiculescu M 2006 The role of cytokines in nonalcoholic steatohepatitis. A review. Journal of Gastrointestinal and Liver Diseases 15 363-373.

Darras VM, Houbrechts AM \& Van Herck SL 2015 Intracellular thyroid hormone metabolism as a local regulator of nuclear thyroid hormone receptor-mediated impact on vertebrate development. Biochimica et Biophysica Acta 1849 130-141. (https://doi.org/10.1016/j. bbagrm.2014.05.004)

De Angelis S, Tassinari R, Maranghi F, Eusepi A, Di Virgilio A, Chiarotti F, Ricceri L, Venerosi Pesciolini A, Gilardi E, Moracci G, et al. 2009 Developmental exposure to chlorpyrifos induces alterations in thyroid and thyroid hormone levels without other toxicity signs in CD-1 mice. Toxicological Sciences 108 311-319. (https://doi. org/10.1093/toxsci/kfp017)

De Groef B, Van der Geyten S, Darras VM \& Kühn ER 2006 Role of corticotropin-releasing hormone as a thyrotropin-releasing factor in non-mammalian vertebrates. General and Comparative Endocrinology 146 62-68. (https://doi.org/10.1016/j.ygcen.2005.10.014)

Eddins D, Cerutti D, Williams P, Linney E \& Levin ED 2010 Zebrafish provide a sensitive model of persisting neurobehavioral effects of developmental chlorpyrifos exposure: comparison with nicotine and pilocarpine effects and relationship to dopamine deficits. Neurotoxicology and Teratology 32 99-108. (https://doi.org/10.1016/j. ntt.2009.02.005)

Elsalini OA, von Gartzen J, Cramer M \& Rohr KB 2003 Zebrafish hhex, $\mathrm{nk} 2.1 \mathrm{a}$, and pax2.1 regulate thyroid growth and differentiation downstream of Nodal-dependent transcription factors. Developmental Biology 263 67-80. (https://doi.org/10.1016/s00121606(03)00436-6)

Faul F, Erdfelder E, Lang AG \& Buchner A 2007 G*Power 3: a flexible statistical power analysis program for the social, behavioral, and biomedical sciences. Behavior Research Methods 39 175-191. (https:// doi.org/10.3758/bf03193146)

Fornes O, Castro-Mondragon JA, Khan A, van der Lee R, Zhang X, Richmond PA, Modi BP, Correard S, Gheorghe M, Baranasic D, et al. 2020 JASPAR 2020: update of the open-access database of transcription factor binding profiles. Nucleic Acids Research $\mathbf{4 8}$ D87-D92. (https://doi.org/10.1093/nar/gkz1001)

Guo C, Chen X, Song H, Maynard MA, Zhou Y, Lobanov AV, Gladyshev VN, Ganis JJ, Wiley D, Jugo RH, et al. 2014 Intrinsic expression of a multiexon type 3 deiodinase gene controls zebrafish embryo size. Endocrinology 155 4069-4080. (https://doi.org/10.1210/ en.2013-2029)

Gutleb AC, Cambier S \& Serchi T 2016 Impact of endocrine disruptors on the thyroid hormone system. Hormone Research in Paediatrics $\mathbf{8 6}$ 271-278. (https://doi.org/10.1159/000443501)

Houbrechts AM, Delarue J, Gabriels IJ, Sourbron J \& Darras VM 2016 Permanent deiodinase type 2 deficiency strongly perturbs zebrafish development, growth, and fertility. Endocrinology 157 3668-3681. (https://doi.org/10.1210/en.2016-1077)

IARC 2001 IARC Monographs on the Evaluation of Carcinogenic Risks to Humans. Lyon, France: International Agency for Research on Cancer. (available at: https://monographs.iarc.fr/wp-content/ uploads/2018/06/mono79.pdf)

Jansen MS, Cook GA, Song S \& Park EA 2000 Thyroid hormone regulates carnitine palmitoyltransferase Ialpha gene expression through elements in the promoter and first intron. Journal of Biological Chemistry 275 34989-34997. (https://doi.org/10.1074/jbc. M001752200)

Jarque S, Fetter E, Veneman WJ, Spaink HP, Peravali R, Strahle U \& Scholz S 2018 An automated screening method for detecting compounds with goitrogenic activity using transgenic zebrafish embryos. PLoS ONE 13 e203087. (https://doi.org/10.1371/journal. pone.0203087)

Jeong SH, Kim BY, Kang HG, Ku HO \& Cho JH 2006 Effect of chlorpyrifos-methyl on steroid and thyroid hormones in rat FO- and F1-generations. Toxicology 220 189-202. (https://doi.org/10.1016/j. tox.2006.01.005)

Kimmel CB, Ballard WW, Kimmel SR, Ullmann B \& Schilling TF 1995 Stages of embryonic development of the zebrafish. Developmental Dynamics 203 253-310. (https://doi.org/10.1002/aja.1002030302)

Leemans M, Couderg S, Demeneix B \& Fini JB 2019 Pesticides With potential thyroid hormone-disrupting effects: a review of recent data. Frontiers in Endocrinology 10 743. (https://doi.org/10.3389/ fendo.2019.00743)

Levin ED, Sledge D, Roach S, Petro A, Donerly S \& Linney E 2011 Persistent behavioral impairment caused by embryonic methylphenidate exposure in zebrafish. Neurotoxicology and Teratology 33 668-673. (https://doi.org/10.1016/j.ntt.2011.06.004)

Marelli F \& Persani L 2017 How zebrafish research has helped in understanding thyroid diseases. F1000Research 6 2137. (https://doi. org/10.12688/f1000research.12142.1) 
Marians RC, Ng L, Blair HC, Unger P, Graves PN \& Davies TF 2002 Defining thyrotropin-dependent and -independent steps of thyroid hormone synthesis by using thyrotropin receptor-null mice. PNAS 99 15776-15781. (https://doi.org/10.1073/pnas.242322099)

Marlatt VL, Gerrie E, Wiens S, Jackson F, Moon TW \& Trudeau VL 2012 Estradiol and triiodothyronine differentially modulate reproductive and thyroidal genes in male goldfish. Fish Physiology and Biochemistry 38 283-296. (https://doi.org/10.1007/s10695-011-9506-z)

McCurley AT \& Callard GV 2008 Characterization of housekeeping genes in zebrafish: male-female differences and effects of tissue type, developmental stage and chemical treatment. BMC Molecular Biology 9 102. (https://doi.org/10.1186/1471-2199-9-102)

Mehran L, Amouzegar A, Bakhtiyari M, Mansournia MA, Rahimabad PK, Tohidi M \& Azizi F 2017 Variations in serum free thyroxine concentration within the reference range predicts the incidence of metabolic syndrome in non-obese adults: a cohort study. Thyroid $\mathbf{2 7}$ 886-893. (https://doi.org/10.1089/thy.2016.0557)

Mullur R, Liu YY \& Brent GA 2014 Thyroid hormone regulation of metabolism. Physiological Reviews 94 355-382. (https://doi. org/10.1152/physrev.00030.2013)

Opitz R, Maquet E, Zoenen M, Dadhich R \& Costagliola S 2011 TSH receptor function is required for normal thyroid differentiation in zebrafish. Molecular Endocrinology 25 1579-1599. (https://doi. org/10.1210/me.2011-0046)

Oppenheimer JH, Schwartz HL, Mariash CN, Kinlaw WB, Wong NC \& Freake HC 1987 Advances in our understanding of thyroid hormone action at the cellular level. Endocrine Reviews 8 288-308. (https://doi. org/10.1210/edrv-8-3-288)

Porreca I, De Felice E, Fagman H, Di Lauro R \& Sordino P 2012 Zebrafish bcl2l is a survival factor in thyroid development. Developmental Biology 366 142-152. (https://doi.org/10.1016/j.ydbio.2012.04.013)

Porreca I, DAngelo F, De Franceschi L, Matte A, Ceccarelli M, Iolascon A, Zamo A, Russo F, Ravo M, Tarallo R, et al. 2016 Pesticide toxicogenomics across scales: in vitro transcriptome predicts mechanisms and outcomes of exposure in vivo. Scientific Reports 6 38131. (https://doi.org/10.1038/srep38131)

Porreca I, Ulloa-Severino L, Almeida P, Cuomo D, Nardone A, Falco G, Mallardo M \& Ambrosino C 2017 Molecular targets of developmental exposure to bisphenol A in diabesity: a focus on endoderm-derived organs. Obesity Reviews 18 99-108. (https://doi.org/10.1111/ obr.12471)

Postiglione MP, Parlato R, Rodriguez-Mallon A, Rosica A, Mithbaokar P, Maresca M, Marians RC, Davies TF, Zannini MS, De Felice M, et al. 2002 Role of the thyroid-stimulating hormone receptor signaling in development and differentiation of the thyroid gland. PNAS $\mathbf{9 9}$ 15462-15467. (https://doi.org/10.1073/pnas.242328999)

Radenne A, Akpa M, Martel C, Sawadogo S, Mauvoisin D \& Mounier C 2008 Hepatic regulation of fatty acid synthase by insulin and T3: evidence for T3 genomic and nongenomic actions. American Journal of Physiology: Endocrinology and Metabolism 295 E884-E894. (https://doi. org/10.1152/ajpendo.90438.2008)

Reale C, Porreca I, Russo F, Marotta M, Roberto L, Russo NA, Carchia E, Mallardo M, De Felice M \& Ambrosino C 2018 Genetic background and window of exposure contribute to thyroid dysfunction promoted by low-dose exposure to 2,3,7,8-tetrachlorodibenzo-p-dioxin in mice Scientific Reports 8 16324. (https://doi.org/10.1038/s41598-018-34427-2)

Reale C, Russo F, Credendino SC, Cuomo D, De Vita G, Mallardo M, Pennino F, Porreca I, Triassi M, De Felice M, et al. 2019 A toxicogenomic approach reveals a novel gene regulatory network active in in vitro and in vivo models of thyroid carcinogenesis. International Journal of Environmental Research and Public Health 16 122. (https://doi.org/10.3390/ijerph16010122)

Richendrfer H \& Creton R 2013 Automated high-throughput behavioral analyses in zebrafish larvae. Journal of Visualized Experiments $\mathbf{7 7}$ e50622. (https://doi.org/10.3791/50622)

Richendrfer H, Pelkowski SD, Colwill RM \& Creton R 2012 Developmental sub-chronic exposure to chlorpyrifos reduces anxietyrelated behavior in zebrafish larvae. Neurotoxicology and Teratology $\mathbf{3 4}$ 458-465. (https://doi.org/10.1016/j.ntt.2012.04.010)

Schlaepfer IR \& Joshi M 2020 CPT1A-mediated fat oxidation, mechanisms, and therapeutic potential. Endocrinology 161 bqz046. (https://doi.org/10.1210/endocr/bqz046)

Shao H, Mohamed EM, Xu GG, Waters M, Jing K, Ma Y, Zhang Y, Spiegel S, Idowu MO \& Fang X 2016 Carnitine palmitoyltransferase 1A functions to repress FoxO transcription factors to allow cell cycle progression in ovarian cancer. Oncotarget 7 3832-3846. (https://doi. org/10.18632/oncotarget.6757)

Sinha RA, Singh BK \& Yen PM 2018 Direct effects of thyroid hormones on hepatic lipid metabolism. Nature Reviews: Endocrinology 14 259-269. (https://doi.org/10.1038/nrendo.2018.10)

Taki-Eldin A, Zhou L, Xie HY, Chen KJ, Yu D, He Y \& Zheng SS 2012 Triiodothyronine attenuates hepatic ischemia/reperfusion injury in a partial hepatectomy model through inhibition of proinflammatory cytokines, transcription factors, and adhesion molecules. Journal of Surgical Research 178 646-656. (https://doi.org/10.1016/j. jss.2012.05.069)

Tzivion G, Dobson M \& Ramakrishnan G 2011 FoxO transcription factors; regulation by AKT and 14-3-3 proteins. Biochimica et Biophysica Acta 1813 1938-1945. (https://doi.org/10.1016/j. bbamcr.2011.06.002)

Van der Vos KE \& Coffer PJ 2008 FOXO-binding partners: it takes two to tango. Oncogene 27 2289-2299. (https://doi.org/10.1038/onc.2008.22)

Vanderpump MP 2011 The epidemiology of thyroid disease. British Medical Bulletin 99 39-51. (https://doi.org/10.1093/bmb/ldr030)

Videla LA, Fernandez V, Vargas R, Cornejo P, Tapia G, Varela N, Valenzuela R, Arenas A, Fernandez J, Hernandez-Rodas MC, et al. 2016 Upregulation of rat liver PPARalpha-FGF21 signaling by a docosahexaenoic acid and thyroid hormone combined protocol. BioFactors 42 638-646. (https://doi.org/10.1002/biof.1300)

Wang Y, Lv L, Yu Y, Yang G, Xu Z, Wang Q \& Cai L 2017 Single and joint toxic effects of five selected pesticides on the early life stages of zebrafish (Denio rerio). Chemosphere 170 61-67. (https://doi. org/10.1016/j.chemosphere.2016.12.025)

Westerfield M 1995 The Zebrafish Book: A Guide for the Laboratory Use of Zebrafish (Danio rerio). Eugene, OR, USA: University of Oregon Press.

Xia M \& Zhu Y 2013 FOXO3a involvement in the release of TNF-alpha stimulated by ATP in spinal cord astrocytes. Journal of Molecular Neuroscience 51 792-804. (https://doi.org/10.1007/s12031-013-0067-8)

Yang D, Lauridsen H, Buels K, Chi LH, La Du J, Bruun DA, Olson JR, Tanguay RL \& Lein PJ 2011 Chlorpyrifos-oxon disrupts zebrafish axonal growth and motor behavior. Toxicological Sciences 121 146-159. (https://doi.org/10.1093/toxsci/kfr028)

Zada D, Blitz E \& Appelbaum L 2017 Zebrafish - an emerging model to explore thyroid hormone transporters and psychomotor retardation. Molecular and Cellular Endocrinology 459 53-58. (https://doi. org/10.1016/j.mce.2017.03.004)

Zoeller TR 2010 Environmental chemicals targeting thyroid. Hormones 9 28-40. (https://doi.org/10.14310/horm.2002.1250)

Received in final form 13 July 2020

Accepted 23 July 2020

Accepted Manuscript published online 23 July 2020 https://joe.bioscientifica.com https://doi.org/10.1530/JOE-20-0134 (c) 2020 Society for Endocrinology Published by Bioscientifica Ltd. Printed in Great Britain 